Recibido: 14 diciembre 2015 Aceptado: 1 julio 2016 Publicado: 29 Julio 2016 Cita: Jiménez Morales, B. (2016). «EI tabú en el habla de Granada: análisis sociolingüístico». Normas 6, 29-52. doi: 10.7203/Normas.6.8151

\section{El tabú en el habla de Granada: análisis sociolingüístico}

\author{
TABOO IN GRANADA'S SPOKEN LANGUAGE: \\ SOCIOLINGUISTIC STUDY
}

\author{
Belén Jiménez Morales
}

Universidad de Granada

Resumen:

Este trabajo pretende analizar y caracterizar, desde un punto de vista sociolingüístico, la expresión del tabú en el habla de Granada. Se elige el corpus oral del equipo de investigación PRESEEA-Granada (Moya, coord., 2007-2009) ya que fue configurado desde un principio con un enfoque puramente sociolingüístico $y$, en consecuencia, resulta ideal para poder aplicar técnicas variacionistas por sexo, edad y nivel de instrucción. En este trabajo se presentan los resultados obtenidos tras analizar todas las variables sociolingüísticas con los factores lingüísticos y pragmáticos propuestos.

PALABRAS CLAVE: tabú, interdicción, sociolingüística, variacionismo, disfemismo, eufemismo, ortofemismo.

\section{Abstract:}

This paper aims to analyze and typify, from a sociolinguistic point of view, the expression of taboo in Granada's spoken language. Our base is the oral corpus gathered by the research group PRESEEAGranada (Moya, coord., 2007-2009) due to its purely sociolinguistic conception and approach. With this corpus, we are able to apply the variationist techniques of sex, age and education. In this paper we show the results obtained after analyzing every sociolinguistic variable with the proposed linguistic and pragmatic factors.

KEYWORDS: taboo, interdiction, sociolinguistic, variationism, dysphemism, euphemism, orthophemism. 
Calvo Shadid (2008) expone la idea de Grimes (1978: 3-6) quien, siguiendo a Leach (1967), defiende que la «interdicción es parte del proceso de adquisición de la lengua, de la cultura, del aprendizaje social» y, en consecuencia, "el tabú está presente en la vida del ser humano de todas las épocas». Por tanto, se aplica a lugares, acciones, personas, situaciones y a la lengua (Calvo Shadid, 2011). Cualquier elemento de los anteriormente citados que conlleve un peligro, restricción o anormalidad es susceptible de ser interdicto por mecanismos sociales y emocionales que se reflejan en el habla a través de mecanismos léxicos y semánticos.

En el transcurso de los siglos, el tabú ha sido estudiado por diversas disciplinas que han encontrado interesante determinar qué factores influyen en su expresión y qué naturaleza tienen, ya sean motivos psicológicos, cognitivos, sociolingüísticos u otros. Por un lado, a lo largo del siglo XX, antropólogos, etnólogos y psicólogos sentaron las bases del estudio conceptual y filosófico del tabú. Por otro lado, la década de los años setenta marca un antes y un después en el tratamiento del concepto de realidad tabuizada desde el punto de vista lingüístico (Martínez Valdueza, 1998: 107). En el primer periodo, fueron expertos del campo de la lexicología, lexicografía y la semántica los que analizaron, sobre todo, el tabú sexual. Martínez Valdueza (1998) señala que hubo pocas investigaciones desde enfoques dialectológicos. En el segundo periodo, estudios de pragmática, sociolingüística y lingüística cognitiva se centran en conocer no solo el origen del tabú sino también su funcionamiento. Recientemente, el estudio de Pizarro (2013) ha supuesto un paso más hacia el estudio del tabú desde el enfoque de la sociolingüística cognitiva.

Tanto el enfoque pragmático-cognitivo más reciente como los de Kany (1960), Montero (1981) y Casas (2005) coinciden en clasificar las diferentes opciones para expresar el tabú en eufemísticas y disfemísticas. Además de estas, Pizarro (2013) se basa en Allan y Burridge (2006) para establecer una tercera opción: el ortofemismo.

Además, el tabú también se puede clasificar según sus causas psicológicas y las esferas conceptuales en las que opera. Cestero (2015a) establece cuatro categorías con el objetivo de organizar tanto las realidades tabuizadas como las expresiones que las representan lingüísticamente. Así, citando a Montero (1981) establece la esfera mágico-religiosa, la sexual, la escatológica y la social (motivadas por el miedo, la decencia, el pudor y el respeto, respectivamente). No obstante, por la naturaleza de las expresiones, estos grupos no se consideran de forma aislada, sino complementaria, teniendo siempre en cuenta su contexto. Por tanto, para poder catalogar las expresiones lingüísticas interdictas de una manera más sistemática, Cestero (2015a) también considera variables de corte pragmático, a saber, la función comunicativa (referencial, no referencial, apelativa, expresiva y marcadora de estilo) y la finalidad (encubrir, atenuar, realzar e informar).

Hasta hace relativamente poco se había seguido un análisis descriptivo y teórico de textos fundamentalmente literarios como metodología de estudio. Posteriormente, trabajos como los de López Morales (1990, 2001, 2005), Martínez Valdueza (1995), Drange (1997) y Calvo Shadid (2008) abren camino a una metodología basada en cuestionarios y entrevistas orales. Incluso Pizarro (2013) llega a crear un corpus específico. Sin embargo, todos ellos analizan únicamente el tabú en la esfera sexual. Es Cestero (2015a) quien propone un marco metodológico para el análisis sociolingüístico de las realidades interdictas en las diversas esferas en la interacción oral y en un registro medio de lengua.

\section{HIPÓTESIS Y OBJETIVOS}

A partir de este tipo de corpus y los materiales recopilados, se plantean las siguientes hipótesis de investigación.

En primer lugar, se presupone que las mujeres emplearían menos expresiones directas que los hombres y menos expresiones que tengan que ver con lo sexual o escatológico. La referencia a la esfera mágico-religiosa sería eminentemente neutra.

En segundo lugar, sería más común encontrar expresiones directas en función expresiva y finalidad enfática. 
En tercer lugar, cabe esperar que los datos de este estudio tengan una relación de similitud con el estudio que Cestero (2015) ha llevado a cabo en el habla de Madrid², aunque se prevén algunas diferencias.

El objetivo de este trabajo es ofrecer una caracterización y un análisis del uso de los conceptos tabuizados y de las referencias lingüísticas a realidades interdictas en el habla de Granada, determinar qué factores sociolingüísticos influyen en su funcionamiento y comparar los resultados con los patrones sociopragmáticos que ha establecido Cestero para el habla de Madrid. Los objetivos específicos que se pretenden alcanzar son los siguientes:

- Dar cuenta del uso y la frecuencia de aparición de palabras que hacen referencia a realidades tabuizadas en el habla de Granada.

- Identificar los recursos más comunes entre los hablantes para expresar dichos conceptos, la función que cumplen en el discurso y su finalidad.

- Conocer la variabilidad del fenómeno según las variables de sexo, edad y nivel de instrucción de los hablantes.

- Comparar los resultados obtenidos en este trabajo con los datos que aporta Cestero en su investigación sobre el corpus PRESEEA-Madrid (distrito de Salamanca).

\section{Metodología}

Este trabajo, sigue las consideraciones metodológicas propuestas por el macroproyecto PRESEEA en general y por el equipo PRESEEA-Granada en particular.

\subsection{El corpus}

El corpus en el que se basa esta investigación fue elaborado por investigadores del Departamento de Lengua Española de la Universidad de Granada coordinados por Moya Corral (2007-9).

El equipo de PRESEEA-Granada sigue las aportaciones de Moreno Fernández (1990), López Morales (1994), Milroy y Gordon (2003), Hernández Campoy y Almeida (2005) y Lavob (1983) para determinar la recogida de materiales: la entrevista semidirigida y poco estructurada. La entrevistadora debe guiar la conversación según unos temas previamente establecidos, pero centrándose, sobre todo, en conseguir la espontaneidad y naturalidad del informante. Los módulos temáticos del macroproyecto incluyen aspectos como la familia y la amistad, las costumbres, el peligro de muerte o las anécdotas importantes de la vida. Concretamente en el equipo de Granada se incluyen temas como la infancia, los juegos, el matrimonio, el trabajo, los hijos, los viajes, los problemas sociales, etc. Como indica Cestero (2015a), para el estudio de las realidades interdictas, algunos de los módulos temáticos «favorecen, incluso, la alusión a realidades y conceptos tabú». Esta variedad de temas, además, permite recoger los distintos tipos discursivos del habla, como son el descriptivo, el narrativo, el argumentativo, el expositivo y el dialogal-conversacional (Moya, coord., 2009: 44).

\subsection{Las variables}

Dada la interdependencia que existe entre la expresión del tabú y su contexto comunicativo, se incorporan variables pragmáticas (interdicción, expresión, finalidad y función), además de las variables sociales de pre-estratificación que requieren este tipo de estudios de enfoque sociolingüístico.

\subsubsection{Variables pragmáticas}

\subsubsection{Interdicción}

Este trabajo toma el apunte metodológico de Cestero (2015b: 11) para la clasificación general de las realidades tabú. Estos son los cuatro tipos de interdicción provenientes de las cuatros esferas interdictas básicas:

\footnotetext{
${ }^{2}$ Tales similitudes han de ser propiciadas por la metodología seguida, el tipo de corpus base y la adscripción al proyecto PRESEEA 
- Interdicción mágico-religiosa. Forma parte del tabú ancestral y su motivación suele ser el miedo. Se distingue entre la religión (deidad y otras entidades) y, como subesferas, lo sobrenatural, la muerte y la enfermedad (ejemplos 1 y 2 ).

- Interdicción sexual. Junto con la escatológica y la social, forma parte del considerado tabú social. Su motivación suele ser la decencia. Se incluyen partes erógenas del cuerpo o relacionadas con el sexo y ropa que las tapa así como la desnudez, procesos y fluidos fisiológicos, prácticas sexuales, conductas y lugares, cualidades relacionadas con la atracción sexual, condiciones sexuales y, sobre todo, relaciones socioafectivas asociadas a la práctica sexual, estados producto de tales relaciones y personas implicadas en ellas, (ejemplos 3 y 4).

- Interdicción escatológica. Su motivación es el pudor. Se tienen en cuenta actos de evacuación, partes del cuerpo implicadas, residuos escatológicos y, especialmente, lugar para realizar las necesidades físicas, (ejemplos 5 y 6 ).

- Interdicción social. Su motivación es la necesidad de respeto y delicadeza. Atiende a diferencias sociales entre personas (económicas o laborales), relaciones familiares no siempre deseables y sus efectos o entidades relacionadas, carácter delictivo, defectos o rasgos físicos no deseables, defectos psíquicos, raza, etnia o grupo cultural asociados a comportamientos delictivos y, sobre todo, edad avanzada y no deseable, (ejemplos 7, 8 y 9).

(1) Esfera mágico religiosa

I: [...] y y recuerdo una anécdota/ que es muy decisiva/ muy espiritual/// que yo estaba una crisis// ee sentimental (fragmento ininteligible) muy fuerte// ts y estaba yo en misa// en la parroquia de Montserrat// y yo estaba allí/ delante del altar/ y le hablaba con Dios y le decía Dios mío/ yo necesito saber que puedo hacer yo con vida// necesito que me ilumines// ¿no?//

\section{[32H-GR08]}

(2) Esfera mágico religiosa

I: le dio un ictus/ y eso/ pierdes la memoria... la forma de expresar y todo/ pero lo que es el campo//eso no se le olvida

[GRAN-H11-038]

\section{(3) Esfera sexual}

I: (tiempo = 10:55) lo puedes evitar siempre// ya otra cosa es que vaya el problema directamente a ti// que a lo mejor tú vas al servicio o estás bebiéndote algo// va tu novia al servicio y ya ahí le to- le tocan (simultáneo: $\mathrm{E}=$ si) el culo/ pues ya está el típico gracioso y «qué pasa» pues ya está

\section{[GRAN-H11-037]}

(4) Esfera sexual

I: [...] yo/ yo no los veo los botellones/ los veo en la tele/ pero// que eso verdaderamente está muy mal// eso debían de quitarlo/// vamos/ es/ es/ era prohibirlo terminantemente porque el día de La Cruz no me digas tú a mí// que eso ha sido un día de La Cruz// Las Cruces que eran antes/ que// que cerraba el comercio por la tarde/ que te arreglabas/ que salías// que ibas a ver esta cruz/ que ibas a ver la otra// con ese orden/ sí la gente cantando// bailando/ tocando las castañuelas mm muy bien// pero eso con esos botellones/ esa vergüenza// las niñas desnudas/// en la calle/ vamos/ vamos/vamos/ vamos/// eso no// eso que debían de prohibirlo el botellón//

\section{[GRAN-M31-052]}

(5) Esfera escatológica

l: juh! de niño/ mira// jugábamos en la placeta/ había una placeta allí en la calle Elvira/ al lado de donde está el pilar// jugábamos a la pelota/// y en otra placetilla que/ en nuestra casa que había que era donde estaba el horno también// que allí jugábamos/ pero allí jugábamos menos/ porque// la dueña de la casa del horno// era una señora mayor// y cuando estábamos jugando a la pelota// nos tiraba la escupidera con orines

[GRAN-H31-049]

(6) Esfera escatológica

l: ya estoy jubilado/ pues mira me dedico// pues mira// te lo voy a/ te lo voy a pres-/// por las mañanas//cuando me levanto// ts// voy al váter/ claro está 
[GRAN-H31-049]

(7) Esfera social

l: [...] el barrio en sí La Chana/// pf yo que sé/// no está mal/ pero/// no sé// no sabría decirte/ me gusta más esto// le veo más/ no te voy a decir chusma (risas) que tampoco es la palabra/// pero no sé/// (fragmento ininteligible) tampoco aquí es que puedas decir// te puedas relacionar mucho//

\section{[GRAN-M12-022]}

\section{(8) Esfera social}

I: [...] pero yo te digo la verdad// antes de que/ y ellos ya lo saben// antes de que mis hijos/ cayeran/// yo digo igual que mi madre// a lo mejor// ts/ es con la/ educación que me han dado ¿no?/ la de/ la doctrina/// pero antes de/ tener un drogadicto o un ladrón// prefiero un maricón// (risas) suena malamente/ a ver si me entiendes// ts/ suena malamente porque a lo mejor estás ofendiendo a las personas esas que// que les dicen maricones/ ¿no? que tienen su sentimientos/// pero/ yo// te digo la verdad// lo peor que puede ser en una familia/// es que dé// un niño o una hija// que sea/ drogadicto/// o ladrón///

[GRAN-M11-042]

\section{(9) Esfera social}

I: (tiempo: 31:22) entonces/ ¿qué qué opino?/ pues opino que eso es de mala educación// opino que se le ha dado a la juventud// a la juventud es/ como si/ si fueran de/mantequilla Flandes// a la/ a la juventud no se le puede tocar// porque pobrecitos// van a darle un trauma// si le dice a una/ un hijo tuyo a un// o alguien/ «no hagas esto/ que esto te va a sentar mal»// no// porque le va a dar un trauma// y luego va a llegar/ y va a matar a la viejecita de enfrente// porque como su mamá no le ha dejado algo// pues esa es la historia

[GRAN-M32-036]

Además de las cuatro esferas tradicionales existe otra esfera muy tabuizada y «muy poblada de elementos y recursos directos e indirectos" (Cestero, 2015b: 15), la llamada esfera políticoeconómica-social (Crespo, 2007). Esta esfera se ha analizado recientemente en relación con los eufemismos dentro del conflicto político-social. Sin embargo, para este estudio, se han considerado solamente las cuatros esferas básicas con el fin de comparar, en particular, con los resultados de Cestero en el habla de Madrid y, en general, con otros que en la actualidad se están llevando a cabo dentro del proyecto PRESEEA.

\subsubsection{Expresión}

Según Montero (1981), Casas (2012a y 2012b) y Pizarro (2013) no existen términos eufemísticos o disfemísticos, sino usos discursivos que hacen referencia a las realidades de forma neutra, directa o indirecta. Se puede decir que, para las unidades que tienen función comunicativa referencial (aquellas que se refieren en la actualidad a conceptos tabuizados) sí existe equivalencia entre expresión directa y disfemismo, expresión neutra y ortofemismo y expresión indirecta y eufemismo y que, por tanto, se pueden clasificar con ambas denominaciones indistintamente. Sin embargo, si los términos tienen función comunicativa no referencial (cuyos valores originales se han desplazado y ya no aluden al concepto tabú al que se referían anteriormente), en la clasificación no existe equivalencia entre expresión directa y disfemismo, por ejemplo, expresiones directas que actualmente no son necesariamente disfemísticas, expresión neutra y ortofemismo o expresión indirecta y eufemismo (Cestero, 2015a: 11). Las distintas formas de expresión consideradas en el análisis de resultados son:

- Expresión directa. Uso de formas lingüísticas que nombran realidades tabuizadas y que desvelan voluntariamente la relación del término escogido con el referente por lo que denotan o connotan (Allan y Burrige 2006: 31 y Pizarro, 2013: 81), (ejemplo 11).

- Expresión neutra. Uso de unidades lingüísticas directas, neutras, literales, formales o estandarizadas que nombran conceptos o realidades tabuizadas y que no están marcadas (Allan y Burrige 2006: 31), (ejemplo 10).

- Expresión indirecta. Uso de recursos lingüísticos variados para referirse, de forma indirecta, a conceptos o realidades tabuizadas, por denotación o connotación (Allan y Burridge, 2006: 33 y Pizarro, 2013: 81), (ejemplo 12).

(10) Expresión directa (ortofemística)

I: pues salieron de va-/ de varios sitios/ salió uno americano/ sa-/ luego también se fue a la parte de Transilvania/ y dicen que hoy por hoy siguen creyendo/ que cuando// abren un ataúd/ y ven que 
una persona están en descomposición cuerpo en des-/ en descomposición// dicen// se siguen creyendo// que son vampiros (simultáneo: $\mathrm{E}=$ juy!) y entonces cogen y les clavan/ estacas de madera travesándoles el corazón hincándolos en la tierra// porque se siguen pensando hoy (simultáneo: $\mathrm{E}=$ joy!) por hoy que son vampiros// (risas) digo «madre mía» pues si eso es lo normal/ que estén descompuestos

[GRAN-M11-040]

(11) Expresión directa (disfemística)

I: Bueno pues// hombre yo los/ los dejo que primero// suelen venir consultando otras veces no consultan por eso// te traen a lo mejor un niño más gordo que/ que no cabe por la puerta/ y/ y consultan porque// tiene un lunar/// y cuando/// cuando lo miras/ dices bueno vamos a ver ieh!// me parece a mí que nos sobran kilillos/ pues entonces ya la madre a lo mejor dice jah! pues eso le quería comentar/ ¿qué hacemos con este niño?/ había que mandarlo al endocrino/// porque ellas piensan que mandándolo a un especialista/ ya ee la bola se la echan a otro

\section{[32M-GR10]}

(12) Expresión indirecta (eufemística)

I: (tiempo: 26:05) juy! a mí me encanta/ en mi oficina la tengo declarada la guerra con la ley del tabaco (risas) para mí ha sido una alegría// (risas) yo tenía una compañera de trabajo/// ahora ya/ ya no está con nosotros// y pf/ ¡madre mía! esa/ esa mujer fumaba// jmadre mía!/ ¡ay! dos compañeros de trabajo// que era jefe// responsable de la delegación// y esta compañera que era era de la administración jmadre mía!/ tú entrabas a trabajar/ abrías por la mañana la puerta y aquello era Londres//

[GRAN-H22-026]

\subsubsection{Finalidad pragmático-discursiva}

Las variables descritas en el apartado anterior no tendrían sentido por sí mismas si no se incluyeran las finalidades discursivas con las que se emite cada expresión, ya que el categórico de eufemístico, disfemístico o ortofemístico deja de ser útil cuando «intervienen razones de interrelación entre los hablantes de un grupo determinado» (García Platero, 2010: 813), por ejemplo, cuando se emplea una palabra malsonante, entendida generalmente como un insulto ("gordo") con una finalidad apelativa de tipo cariñoso o afectiva («mi gordo»). Además, Casas (2012a y 2012b) establece que los mensajes tabuizados atienden a determinados procesos cognitivos de conceptualización, por lo que no se debería hablar de términos eufemísticos per se, sino de términos utilizados con valor eufemístico. Como señala Cestero (2015b: 15), los planteamientos de García Platero y Casas hacen totalmente necesario que el estudio de las realidades tabuizadas se centre primero en la finalidad del mensaje tabuizado para, posteriormente, poder determinar el tipo de expresión. Las variables que se tratan en este punto son producto de la elaboración de Cestero a partir de la propuesta de Crespo (2007) y, en mayor medida, de la base pragmático-cognitiva propuesta por Casas (2012a y 2012b):

- Encubrir. Uso de elementos o expresiones que aluden de manera indirecta a realidades interdictas para evitar las denotaciones o las connotaciones negativas de los términos interdictos neutros y directos, (ejemplo 13).

- Atenuar. Selección de ciertos elementos o expresiones con el fin de rebajar o eliminar la tensión social que supondría el uso de expresiones de referencia directa a realidades interdictas para así evitar amenazas a relaciones sociales o a las imágenes del emisor o del receptor, (ejemplo 14).

- Enfatizar. Exaltación expresiva (realidades interdictas o no), mediante el uso de expresiones o términos que aluden a una determinada realidad o concepto considerado socialmente denostado con objeto de revalorizarlo, (ejemplo 15).

- Informar. Referencia por parte del hablante a conceptos o realidades interdictas con una finalidad puramente informativa, (ejemplo 16).

(13) Encubrir

l: [...] y ya está pues son// totalmente diferentes/ aquí no tienes/ problemas de vecinos/ porque allí/ lo malo que tenía es que eran// todo gente mayor/// y tú ya sabes la gente mayor pf// que para pintar nos las vimos y nos las deseamos que al final no se pintó/ ya lo sabes tú y veremos a ver porque ahora dicen que sí van a pintar// y vamos a tener que poner el dinero

[GRAN-M12-022]

(14) Atenuar

I: que hay un montón de esculturas en todos lados/// ts/ y luego estuvimos en Mónaco/// y luego ya volver a Barcelona/// pero ts/ el viaje no es muy/ barco/ muy gracioso/// en barco estuvimos// 
fue muy simpático// por los animadores que/ que estaban en el barco eran muy simpáticos/ (risas) eran muy graciosos/ había allí un negrillo que se pasaba todo el día bailando// era gracioso estábamos a todas horas de comer en el barco/ eso sí que era gracioso// salimos de Barcelona yo creo que nada más que salir nos dieron de comer un bocadillo// (risas)

\section{[GRAN-H22-026]}

\section{(15) Enfatizar}

I: vale/// pues como ya te he dicho antes/ es una urbanización/// estamos en/ en la urbanización treinta $\mathrm{y} / /$ treinta y dos o treinta y tres vecinos/ tiene seis portales/// mi portal/ tiene cinco vecinos// cinco vecinos/// nos llevamos de puta madre// (simultáneo: $\mathrm{E}$ = si) perdón/ otra vez/// y// somos todos jo-/ gente joven/// y mi piso/ pues tiene tres dormitorios// el salón// una cocinilla

\section{[GRAN-M11-042]}

\section{(16) Informar}

I: y/ exactamente y jugábamos// estábamos todo el día en la calle// eso// ahora se da menos ¿no? pero yo lo entiendo/ y estábamos todo el día en la calle o cuando no estábamos en el colegio/ estábamos.../ pero claro el hecho de estar en la calle no significa que// estabas en la puerta de tu casa// y muy bien muy bien// muy bien/ éramos una pandilla de más o menos todos de la misma edad// niños/ niñas ahí da igual// cuando eres pequeño// (tiempo: 03:01) el sexo es lo de menos ¿no?//

[GRAN-H22-027]

\subsubsection{Función comunicativa}

Teniendo en cuenta las aportaciones de Martínez Valdueza (1998) y la clasificación seguida por Cestero (2015a), en este apartado se distingue entre:

- Función comunicativa referencial. Se utiliza una forma lingüística asociada a una realidad o concepto interdicto para hacer referencia a tal concepto o realidad, (ejemplo 17).

- Función comunicativa de referencia desplazada. Se emplea una expresión lingüística asociada a una realidad o concepto interdicto con un significado diferente, no relacionado con la interdicción original, (ejemplo 18).

- Función apelativa. Se utilizan formas y expresiones con el fin de apelar, insultar o injuriar, (ejemplo 19).

- Función expresiva sin valor referencial. Se emplean formas expletivas producidas como exclamaciones interjectivas, (ejemplo 20).

- Función expresiva marcadora de estilo. Se recurre a formas expletivas que se insertan en construcciones sintácticas, marcando estilo coloquial, (ejemplo 21).

(17) Función comunicativa referencial

I: Lleva unos años porque hemos pasa(d)o una rachilla mala/ unas cuantas operaciones ya de// empezó con el pecho la operaron de de un quiste/ al final era un tumor que era maligno entonces se lo extirparon del pecho/ y después/ últimamente la operaron/ pero ya lleva un período ya que s(e) ha estabiliza(d)o

\section{[31H-GR01]}

(18) Función comunicativa de referencia desplazada

I: pero yo cogía el coche para todo// yo soy de culo en burra// y en moto/ cuando tenía moto entonces en moto para todos lados// moto para arriba/ moto para abajo// pasa que con la lluvia es muy mala la moto/ y con estos fríos/ y aquí es que hace un frío en Granada/

[GRAN-H12-021]

(19) Función apelativa

E: ¿Cambiarán los métodos para ligar?

I: También pueden cambiar (risas) un poquito entonces/ iqué mala es! (risas).

\section{[31M-GR04]}

(20) Función expresiva sin valor referencial

I: [...] también es de ley que un hombre// que tenga vicio// de fumar/ porque es que eso es un vicio// pues el hombre se pueda fumar un cigarro// que tienen que ponerle una mampara al autobús y cortar ve- diez asientos para atrás para los fumadores con unos ventiladores/ pues que los corten/ que para esos pagan/// pero antes de sacar una ley lo que deberían de haber sacado era la... una normativa/ y adecuar las cosas a esa ley/ no sacar la ley ahí fa (simultáneo: E = ya está sí) sí y ahora que si las mamparas/ «es que yo puse un biombo// es que yo puse» «jah! no pero es que el biombo ahora no sirve/ ahora tiene que ser un tabique»/ "coño pues yo ahora no lo quiero hacer»// y claro/ yo eso no lo veo/// no lo veo bien 
[GRAN-H21-043]

(21) Función expresiva marcadora de estilo

I: es más tranquilo// porque meterte allí en/ el Almanjáyar// como que no/// como que no/// porque alli// el que no te vas a encontrar/ que te esté robando// ts/ no es no es/ decir que no vayan// a ver si me entiendes// sino que ahí a ciertas horas// que te tienes que andar con pies de plomo/ ts entonces claro/ yo para estar con los niños// «mira niño no esto»/ o para que le peguen un achuchón// o para que vengan alguien/ o para que vea// cosas como tú has dicho antes// la droga// al típico/ enganchado que no tiene otro jodido// sitio// de ponerse// sino/ en una cuesta donde está bajando la gente

[GRAN-M11-042]

\subsubsection{Variables sociales}

Los informantes se clasifican en hombre o mujer, de primera generación (entre 20 y 34 años), segunda generación (entre 35 y 54 años) o tercera (mayores de 55 años) y, según nivel de instrucción, bajo (si ha recibido educación primaria o ha estado escolarizado un máximo de 10 años), medio (de 10 a 14 años de escolarización) y alto (aproximadamente 15 años de escolarización).

\subsection{La muestra}

Se trata de una muestra por cuotas de afijación uniforme en la cual se estratifica el universo relativo según las tres variables sociales anteriormente descritas.

Para determinar el tamaño de la muestra se tuvieron en cuenta los 237.929 habitantes de Granada en el momento de recogida de los datos. Se tomó un informante por cada 4.406 habitantes (Moya, coord., 2007: 42-43). La tabla 1 muestra la distribución de los informantes según las tres variables de pre-estratificación.

\begin{tabular}{|l|l|l|l|l|l|l|l|}
\hline & $1{ }^{a}$ Generación & \multicolumn{2}{l|}{ 2. $^{\text {a }}$ Generación } & \multicolumn{2}{l|}{ 3. ${ }^{a}$ Generación } & \multirow{2}{*}{ Total } \\
\cline { 2 - 7 } & Hombres & Mujeres & Hombres & Mujeres & Hombres & Mujeres & \\
\hline N. Bajo & 3 & 3 & 3 & 3 & 3 & 3 & 18 \\
\hline N. Medio & 3 & 3 & 3 & 3 & 3 & 3 & 18 \\
\hline N. Alto & 3 & 3 & 3 & 3 & 3 & 3 & 18 \\
\hline Total & 9 & 9 & 9 & 9 & 9 & 9 & 54 \\
\hline
\end{tabular}

Tabla 1. Distribución de la muestra-tipo del proyecto PRESEEA-Granada

\subsection{Tratamiento de los datos}

Tras la obtención del corpus, se leyeron de manera completa las 54 entrevistas y se señalaron, e incluyeron en una tabla, todas aquellas lexías o unidades fraseológicas que hacían referencia a conceptos tabú. Se contabilizaron 602 expresiones relativas a realidades tabuizadas, que fueron codificadas y tabuladas atendiendo al número de informante y a las variables anteriormente citadas. Cabe señalar que se recurrió a la definición lexicográfica para clasificar ciertas unidades que plantearon dudas por su situación en el contexto de habla. El análisis de los datos se realizó con el paquete estadístico IBM ${ }^{\circledR}$ SPSS $^{\circledR}$.

\section{ANÁLISIS DE LOS DATOS}

Para poder responder a las diferentes hipótesis planteadas en este estudio y comparar con los datos recogidos por Cestero (2015b), se han analizado las 602 expresiones relativas a conceptos 0 realidades tabulizadas encontradas en el corpus PRESEEA-Granada. Es necesario destacar que el procedimiento de selección de los materiales analizados por Cestero difiere en número de entrevistas del que se ha seguido en este estudio. Cestero analiza 36 entrevistas (18 correspondientes al distrito de Salamanca y 18 al distrito de Vallecas). De cada grupo escoge a un hombre y una mujer de cada nivel de instrucción y generación (Cestero, 2015b: 9). En el caso de Granada, se analizan 54 entrevistas correspondientes a las conversaciones con tres hombres y tres mujeres de cada nivel de instrucción y generación. Aún así, parece interesante proporcionar una comparación. 
De las 602 expresiones, el 63.6\% se refiere a la esfera social (382 casos), el 21.8\% tiene que ver con la esfera mágico religiosa (131 casos), el $10.6 \%$ corresponde a la esfera sexual (64 casos) y tan solo el $4 \%$ se refiere a la esfera escatológica (24 casos) (gráfico 1).

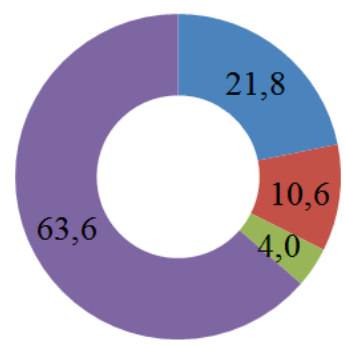

- Mágico-religiosa

- Sexual

Escatológica

$\square$ Social

Gráfico 1. Frecuencia de esferas en el habla de Granada

Así, en conversaciones semidirigidas, los hablantes intentan evitar referirse a realidades que tienen que ver con lo escatológico y, por tanto, se podría considerar que la esfera escatológica es la más tabuizada. Por su parte, la alta frecuencia a las esferas social y, en cierto modo, también a la mágicoreligiosa, hace pensar que no existe tanto reparo a hablar de conceptos o realidades que tienen que ver con ellas.

Si se comparan estos datos con los de Cestero (2015b), se puede decir que la esfera mágicoreligiosa está más presente en el corpus del habla de Granada. La frecuencia de aparición, por orden, de expresiones relacionadas con realidades interdictas según los datos recogidos en el habla de Madrid sería: esfera social, esfera sexual, muy seguida de la esfera mágico-religiosa y, por último, esfera escatológica. En la tabla 2 se comparan las frecuencias del corpus PRESEEA-Granada y del PRESEEA-Madrid:

\begin{tabular}{|l|l|l|}
\hline & Granada & Madrid \\
\hline Esfera mágico-religiosa & $21.8 \%$ & $19.4 \%$ \\
\hline Esfera sexual & $10.6 \%$ & $19.5 \%$ \\
\hline Esfera escatológica & $4 \%$ & $4.6 \%$ \\
\hline Esfera social & $63.6 \%$ & $56.6 \%$ \\
\hline
\end{tabular}

Tabla 2. Frecuencia de esferas en Granada y en Madrid

En cuanto a la forma de expresión (gráfico 2), la mayoría de unidades léxicas son directas, representan un $39.7 \%$ de los casos, seguidas de las neutras, correspondientes al $38.6 \%$ de los casos. En menor proporción, un 21.6\%, se encuentran las unidades indirectas.

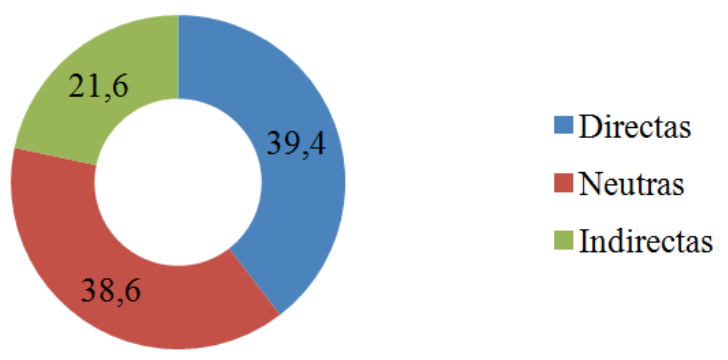

Gráfico 2. Expresión de unidades tabuizadas en el habla de Granada

Cabe señalar que, para todos los apartados del análisis, se ha seguido lo que se considera para este estudio una correlación gradual descendente: en primer lugar, la variante directa; en segundo lugar, la variante neutra; $y$, en tercer lugar, la variante indirecta. Igualmente se podría haber elegido un orden ascendente: indirecta, neutra y directa. La idea fundamental reside en considerar la variante neutra en medio de las otras dos. 
Si se hace un análisis conjunto de función y finalidad, se observa que la mayoría de las ocurrencias se producen en un contexto comunicativo referencial (72.1\%), de las cuales el $39.1 \%$ tienen como objetivo informar, el 19.4\% enfatizar, el 6.8\% atenuar y otro 6.8\% encubrir (gráfico 3).

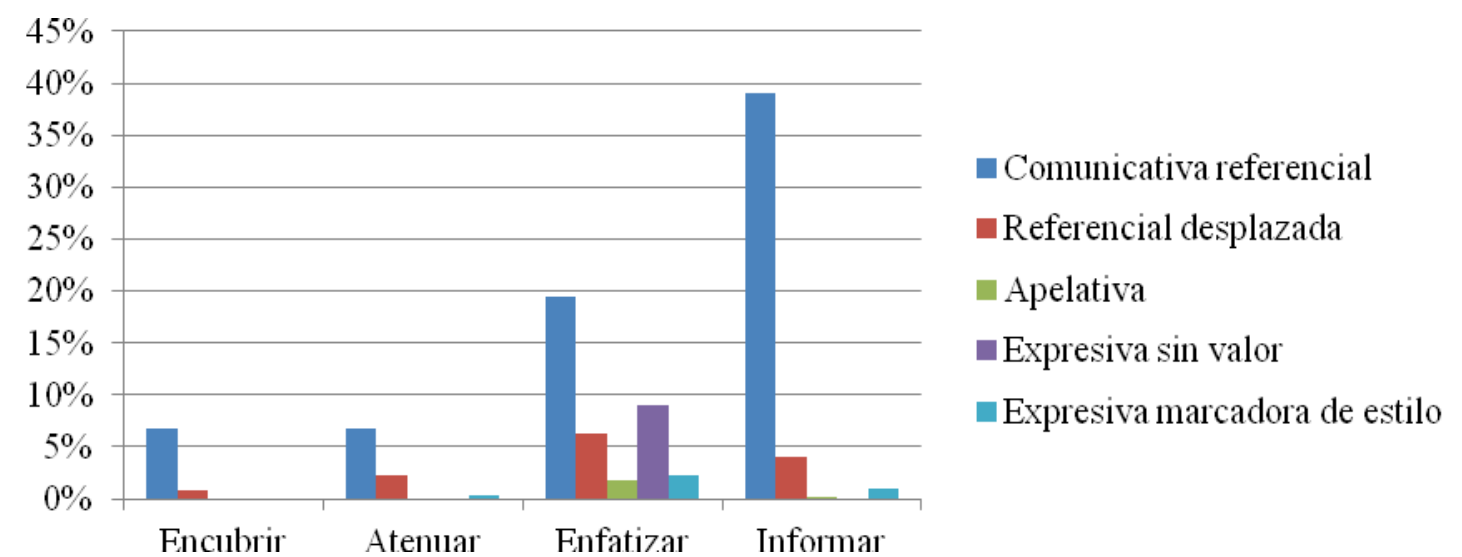

Gráfico 3. Función y finalidad de las realidades tabuizadas

En las tablas 3 y 4 se pueden observar las diferencias por función que existen entre Granada y Madrid. La función «no referencial» en Granada cuenta con una mayor representación, el 27.8\% de la muestra (frente al 13\% en Madrid). Tanto Granada como Madrid coinciden en que la mayoría de expresiones «no referenciales» se emplea para enfatizar. Dentro de ese $27.8 \%$, el $9 \%$ son expresiones interjectivas (un dato similar al $7 \%$ de Cestero). Las expresiones apelativas componen el $1.9 \%$ del total (un $0.8 \%$ en Madrid) y se usan para enfatizar también. Por otro lado, en cuanto a la función referencial desplazada, en Granada representa el 13.4\% de las ocurrencias frente al 5\% de casos hallados por Cestero. Finalmente, las ocurrencias de expresiones utilizadas como marcadores de estilo en Granada suponen el 2.6\% de la muestra frente al $0.1 \%$ de Cestero.

\begin{tabular}{|l|l|l|}
\hline & Granada & Madrid \\
\hline Referencial & $72.1 \%$ & $87.1 \%$ \\
\hline No referencial & $27.8 \%$ & $13 \%$ \\
\hline
\end{tabular}

Tabla 3. Frecuencia de funciones en Granada y en Madrid

De las expresiones no referenciales, Granada destaca en expresiones desplazadas con un $13.4 \%$ de los casos mientras que en Madrid se recurre más a la función expresiva sin valor (a la que Cestero llama «interjectiva»). Las menos comunes son la función apelativa la función marcadora de estilo, aunque en Granada sí parece importante en comparación con Madrid (2.6\% frente al 0.1\% que obtiene Cestero).

\begin{tabular}{|l|l|l|}
\hline & Granada & Madrid \\
\hline Expresiva sin valor(Interjectiva) & $9 \%$ & $7 \%$ \\
\hline Desplazada & $13.4 \%$ & $5 \%$ \\
\hline Apelativa & $1.9 \%$ & $0.8 \%$ \\
\hline Expresiva marcadora de estilo & $2.6 \%$ & $0.1 \%$ \\
\hline \multicolumn{2}{|l}{ Tabla 4. Distribución de las funciones no referenciales }
\end{tabular}

\subsection{Variable sexo}

En primer lugar, se observa que los hombres y las mujeres de Granada utilizan casi la misma cantidad de expresiones que hacen referencia a realidades tabuizadas o interdictas (301 y 298 ocurrencias, respectivamente).

Sin embargo, si se analizan estos datos junto con la forma de expresión, las mujeres emplean un $10 \%$ más de expresiones neutras que los hombres ( $\mathrm{M}: 43.6 \%$ frente a $\mathrm{H}: 33.9 \%$ ) y estos casi un $6 \%$ más de expresiones directas que las mujeres granadinas $(\mathrm{H}: 42.5 \%$ frente a $\mathrm{M}: 36.6 \%)$. La opción indirecta sigue más o menos el mismo esquema para hombres y para mujeres. En el gráfico 
4 se observa que los datos derivados de los hombres siguen un patrón descendente desde la estrategia directa a la indirecta y los de las mujeres, en cambio, presentan un repunte en la expresión neutra.

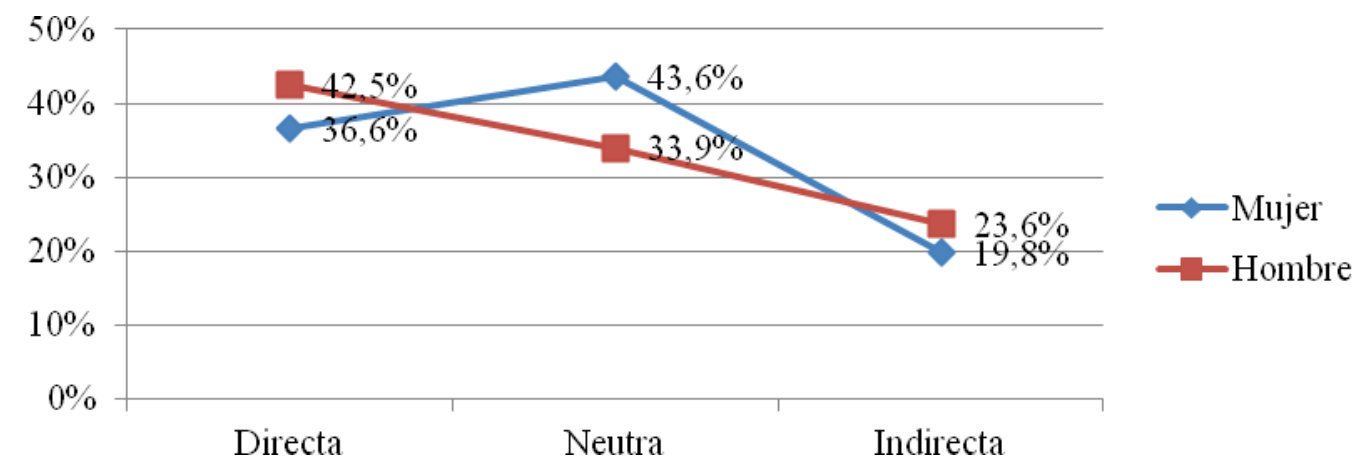

Gráfico 4. Expresión del tabú según el sexo

Comparados con Cestero (gráfico 5), los datos arrojan que las mujeres de Madrid utilizan la estrategia neutra alrededor de un 15\% más que los hombres, al igual que en Granada, y estos, la estrategia directa un 13\% más que las madrileñas. En Madrid los hombres emplean un 3\% más la estrategia indirecta, lo que supone casi la misma proporción que se obtienen en Granada. Por tanto, la diferencia que se observa tiene que ver con el patrón de comportamiento de los hombres granadinos con respecto al resto.

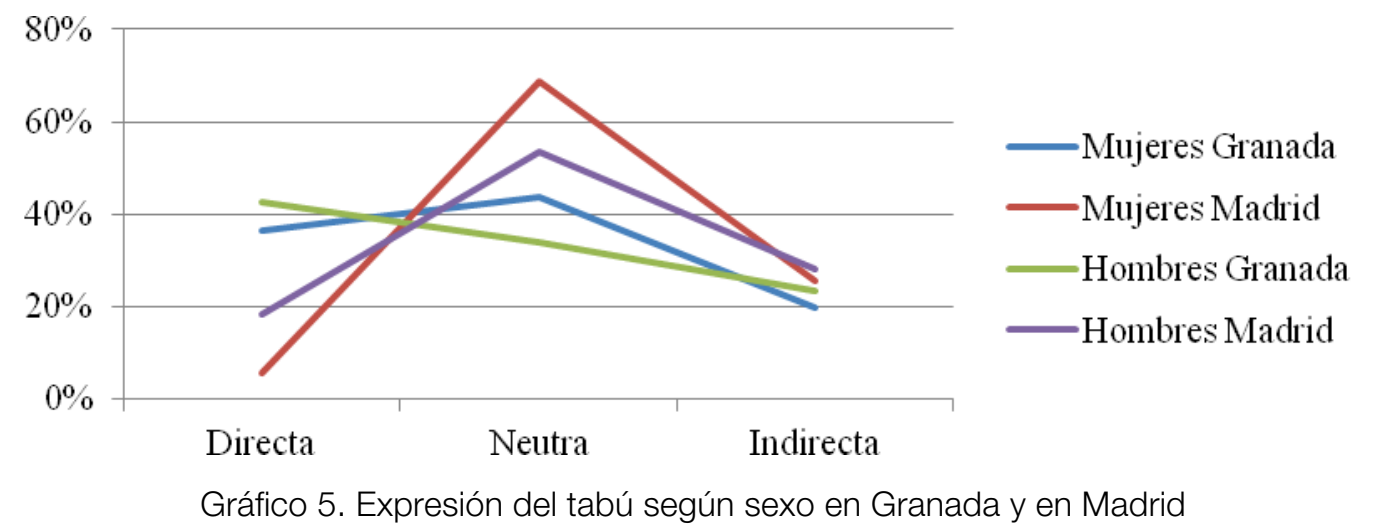

En el análisis por esferas (gráfico 6), las mujeres se refieren en mayor proporción a realidades tabuizadas de la esfera mágico-religiosa que los hombres (M: 25.5\% frente a H: 18.2\%); los hombres emplean más expresiones que tienen que ver con la esfera sexual ( $\mathrm{H}: 14.5 \%$ frente a $\mathrm{M}: 6.7 \%)$ y la escatológica (H: $5 \%$ frente a M: $3 \%)$, aunque esta última es casi inexistente en el corpus manejado, como ya se ha señalado anteriormente, dado su carácter semidirigido. La expresión de conceptos referentes a la esfera social está muy igualada entre mujeres y hombres ( $\mathrm{M}: 64.8 \%$ y H: 62.4\%).

En el habla de Madrid, las mujeres también utilizan más expresiones mágico-religiosas y sociales que los hombres; por su parte, los hombres recurren más a la esfera sexual y la escatológica. 


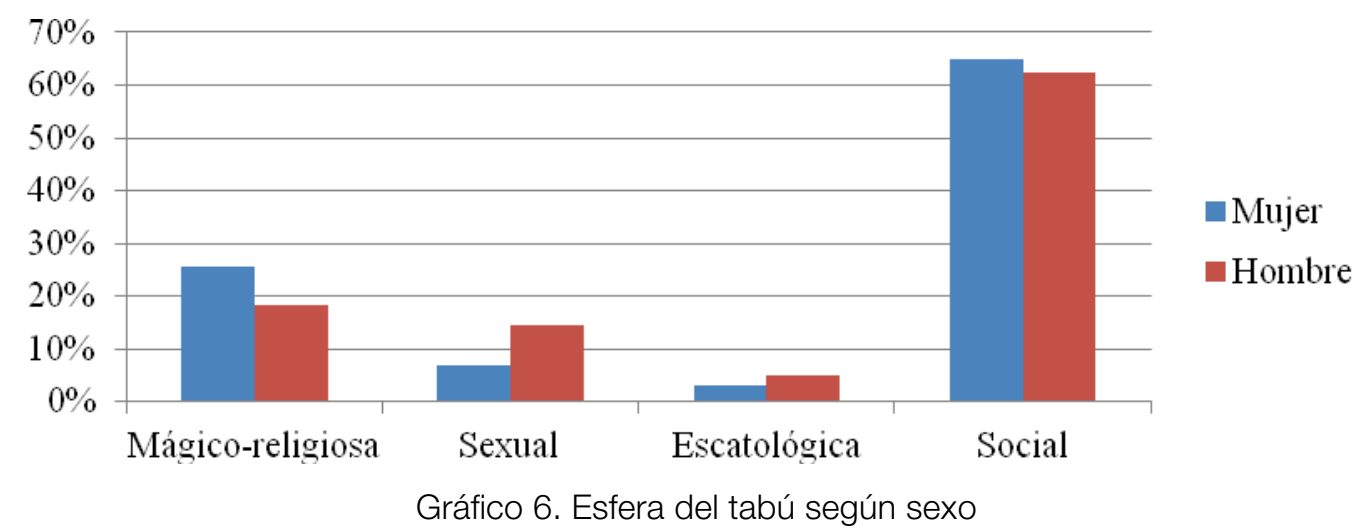

Además del análisis global anterior, este estudio aísla la variable dependiente (expresión del tabú) en sus cuatro variantes (mágico-religioso, sexual, escatológico y social) para poder apreciar la situación sociolingüística más específicamente.

Del total de referencias que los hablantes granadinos hacen a la esfera mágico-religiosa, las mujeres emplean la estrategia directa tan solo el $6.6 \%$ de las veces, la neutra el $76.3 \%$ y la indirecta el $61.1 \%$; y los hombres, para la misma esfera, usan la estrategia directa el $14.5 \%$ de las veces, la neutra el $67.3 \%$ y la indirecta un 18.2\% de las ocurrencias. Así, en el gráfico 7 se observa un patrón de comportamiento similar entre hombres y mujeres en cuanto al uso de las estrategias. No obstante, se observan algunas diferencias, pues si bien las mujeres recurren a las estrategias directa y neutra casi al mismo nivel que los hombres, estos, en cambio presentan un descenso en la estrategia indirecta. Es decir, las mujeres se muestran, aunque sea levemente, más atentas a evitar las formas tabuizadas vinculadas con esta esfera.

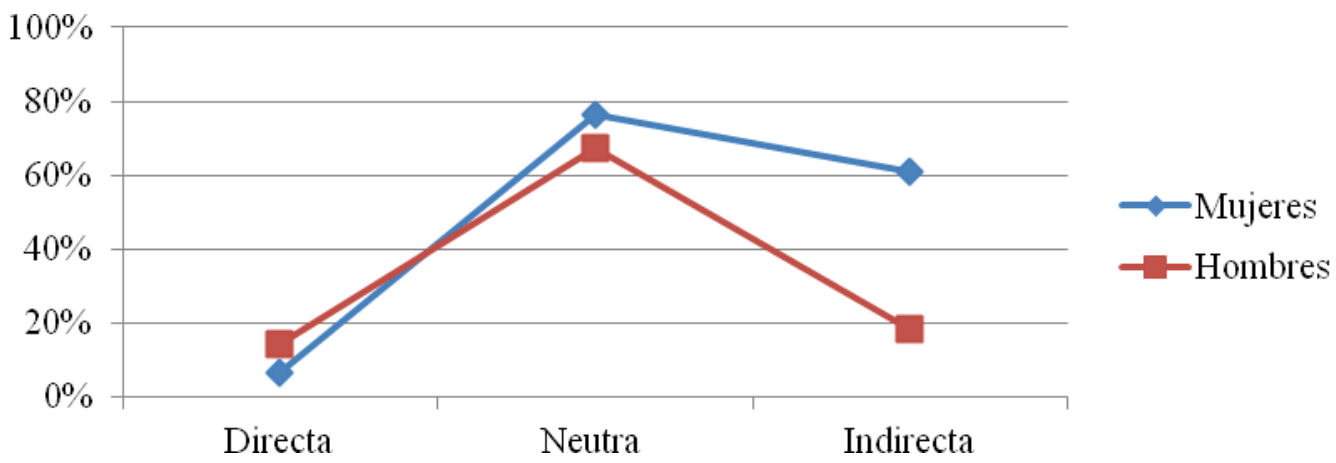

Gráfico 7. Tipo de expresión en la esfera mágico-religiosa: sexo

En cuanto a la esfera sexual, las granadinas emplean la estrategia directa el $50 \%$ de las ocasiones, la neutra el $20 \%$ y la indirecta el $30 \%$; los granadinos, por su parte, usan la estrategia directa el $45.5 \%$ de las veces, la neutra el $6.8 \%$ y la indirecta el $47.7 \%$.

Por tanto, como se observa en el gráfico 8, esta esfera sigue un patrón de comportamiento muy similar al de la esfera mágico-religiosa pero inversa. Es decir, los hombres utilizan más las opciones de los extremos (directa e indirecta) y menos la opción neutra mientras que las mujeres recurren más a la directa, y las estrategias neutra e indirecta disminuyen.

No obstante, es necesario señalar que las mujeres neutralizan mucho más las expresiones relativas a conceptos sexuales tabuizados, mientras que los hombres se refieren a estas utilizando la variante indirecta (eufemística) casi un 20\% más que las mujeres. Por tanto, aunque emplean también más la estrategia directa, los hombres compensan con la estrategia indirecta. Una hipótesis que se plantea como explicación a este fenómeno es que, en el corpus PRESEEA-Granada, el interlocutor (entrevistador) era mujer y, quizás, al tratar esta esfera, los hombres se podrían haber sentido más intimidados o menos cómodos, lo que les hubiese llevado a tratar los conceptos tabuizados de una forma indirecta, eufemística. 


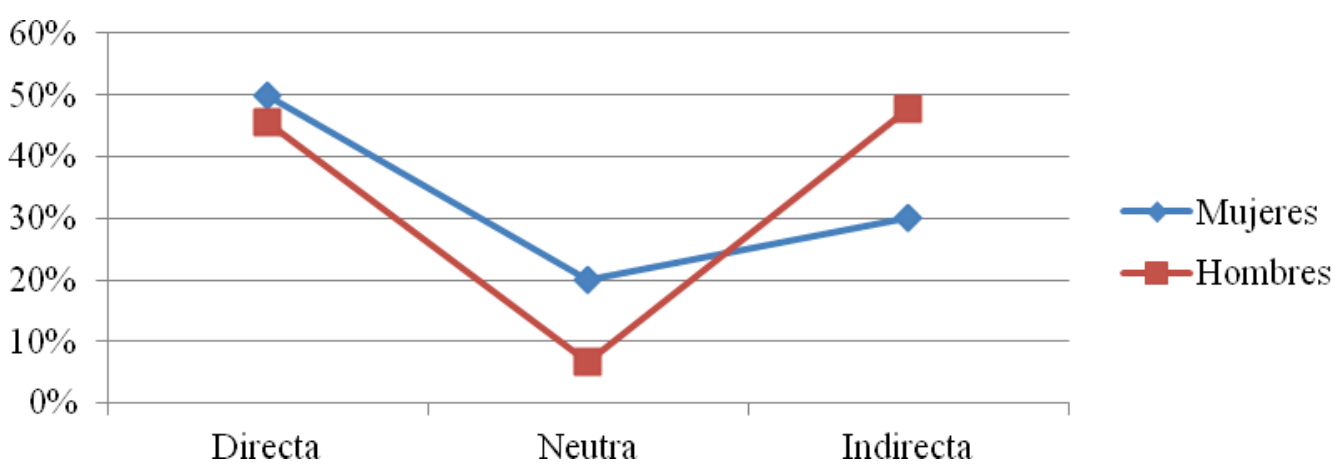

Gráfico 8. Tipo de expresión en la esfera sexual: sexo

En cuanto a la esfera escatológica, las granadinas se refieren a estas expresiones en estrategia directa un 55.6\% de los casos, la neutra un 22.2\% y la indirecta también un 22.2\%; los granadinos, por su parte, emplean la estrategia directa un 33\% de los casos, la neutra en el $26.7 \%$ y la indirecta un $40 \%$ de las ocurrencias.

Como se muestra en el gráfico 9, las mujeres siguen el mismo patrón descrito anteriormente: repunte en la estrategia directa y equilibrio entre la neutra y la indirecta; por su parte, los hombres continúan con un esquema de extremos, aunque las distancias son menores. Dada la naturaleza del corpus manejado, como se sabía de antemano, aparecen muy pocas referencias a esta esfera (tan solo 25). Sin embargo, se puede interpretar que los hombres tienen más reparo a referirse a ella de una manera directa, debido, muy probablemente, al factor interlocutor-mujer.

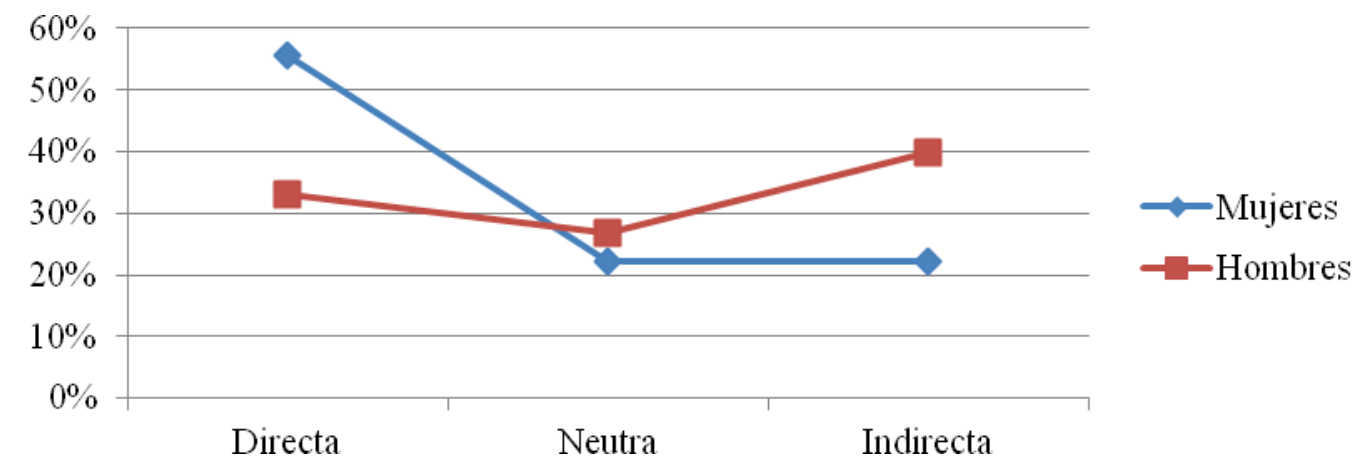

Gráfico 9. Tipo de expresión en la esfera escatológica: sexo

En cuanto a la esfera social, se puede afirmar que no hay diferencia dependiendo si la persona entrevistada es una mujer o un hombre, ya que los datos numéricos son casi idénticos: estrategia directa (M: $46.1 \%$ y $\mathrm{H}: 50.8 \%$ ); estrategia neutra (M: $34.2 \%$ y H: 31\%) y estrategia indirecta (M: $19.7 \%$ y $\mathrm{H}: 18.2 \%)$.

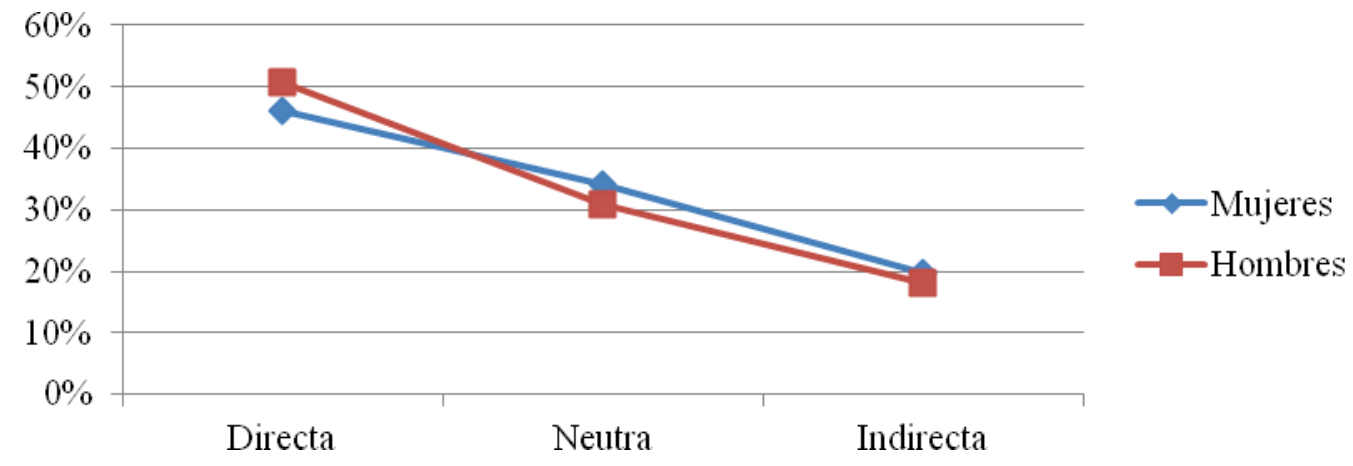

Gráfico 10. Tipo de expresión en la esfera social: sexo 
El último caso de análisis para la variable sexo tiene que ver con la finalidad para la que los hablantes hombres y mujeres utilizan las expresiones tabuizadas. Tanto hombres como mujeres tratan de encubrir, enfatizar e informar en la misma proporción. La única diferencia por sexo se da en la variante atenuar, donde los hombres lo expresan con esa intención un $59.6 \%$ de las ocasiones, frente al $40.4 \%$ de las mujeres. Hay que tener en cuenta que, como se ha analizado anteriormente, los hombres recurren, de manera general, a la estrategia indirecta eufemística con mayor frecuencia que las mujeres, lo que tiene relación directa con el mayor uso de la finalidad atenuar por parte de los granadinos. Así, como se observa en el gráfico 11, existe una polarización entre las finalidades encubrir y atenuar con respecto a las de enfatizar e informar tanto en hombres como en mujeres.

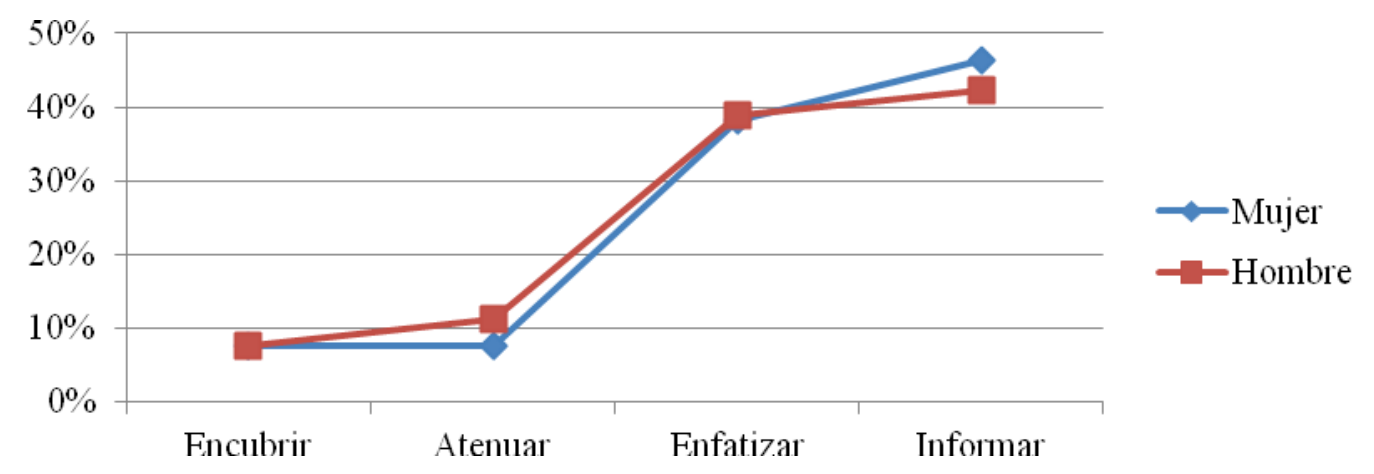

Gráfico 11. Finalidad del tabú según sexo

Con respecto a estos datos recogidos para el habla de Granada, se puede observar en el gráfico 12 cómo en Madrid los casos enfatizar e informar tienen comportamientos diferentes ya que, por un lado, no existe polarización, sino que siguen un patrón más o menos continuo en las variantes encubrir, atenuar y enfatizar para después destacar con mucho en la variante informar; y, por otro lado, las distancias entre madrileñas y madrileños son más grandes, sobre todo en la finalidad enfatizar (H: 26.2\% y M: 10.9\%) e informar (H: 46.9\% y M: 64.4\%).

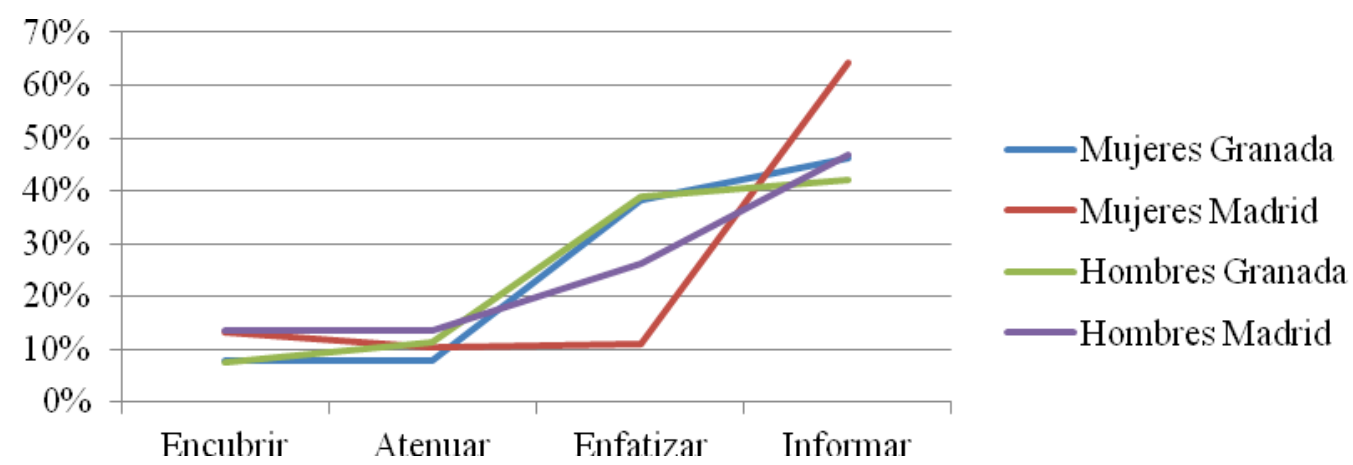

Gráfico 12. Finalidad de tabú según sexo en Granada y en Madrid

\subsection{Variable edad}

En cuanto a la edad de los informantes, los jóvenes emplean un 38.7\% la estrategia directa, un $39.7 \%$ la estrategia neutra y un 21.6\% la indirecta. Ya en la segunda generación se muestra un descenso de formas neutras (31.2\%) y un aumento de formas directas (43.3\%), quedando las formas indirectas más o menos en la misma proporción que en la primera generación (25.5\%). Por último, los hablantes granadinos de la tercera generación usan la expresión neutra (45.7\%) muy por encima de la indirecta (17.8\%) y de la directa (36.5\%). En el gráfico 13 se observa que la variación más notable por nivel generacional estaría en el uso de la expresión neutra, que aumenta considerablemente en los hablantes de mayor edad. 


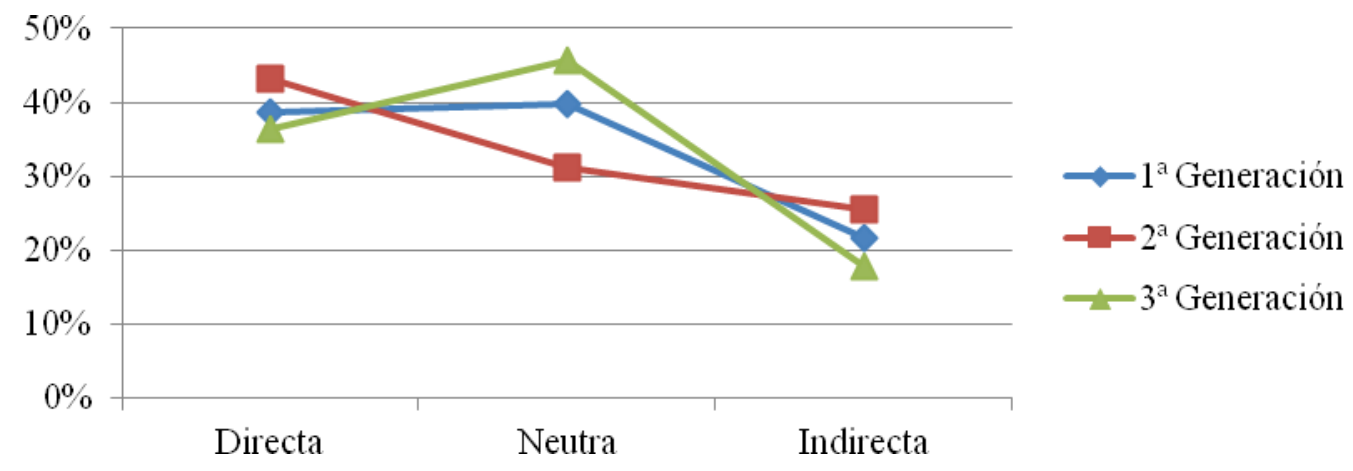

Gráfico 13. Expresión del tabú según la edad

Si se comparan estos datos con los de Madrid (gráfico 14), se observa que, de manera similar a lo que ocurría con el patrón de comportamiento en la variable sexo, los granadinos reparten las tres estrategias de una manera más equilibrada que los madrileños quienes, en cambio, optan fundamentalmente por la neutra.

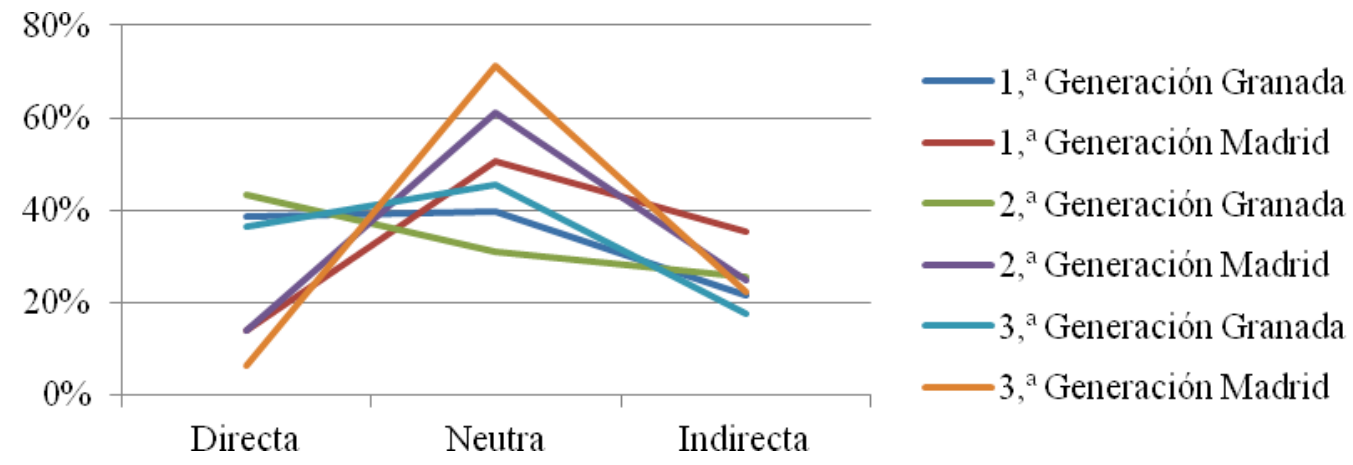

Gráfico 14. Expresión del tabú según edad en Granada y en Madrid

En cuanto a la distribución de esferas según la edad (gráfico 15), los jóvenes se refieren a la esfera mágico-religiosa un $17.9 \%$ de los casos, los adultos aluden a esta en un $19.1 \%$ de las ocasiones y, con diferencia, son los mayores los que más recurren a esta esfera (28.4\%). Por el contrario, los mayores aluden a la esfera sexual en pocas ocasiones (5.6\%) mientras que los jóvenes y adultos lo hacen más frecuentemente (13.3\% y 12.9\%). En cuanto a la esfera escatológica, muy poco frecuente en todas las generaciones, la mayor parte de los casos de la tercera generación pertenecen a un mismo informante que, durante la entrevista semidirigida, por su relación entrevistador/informante (entrevistadora menor que el informante y pariente) encontró suficiente confianza para referirse de forma directa y neutra a dicha esfera. Por último, en cuanto a la esfera social, no se aprecian grandes diferencias: las tres generaciones la utilizan entre un $61.9 \%$ y un $64.6 \%$. En consecuencia, se puede afirmar que la esfera escatológica es la más tabuizada y la esfera social la menos tabuizada.

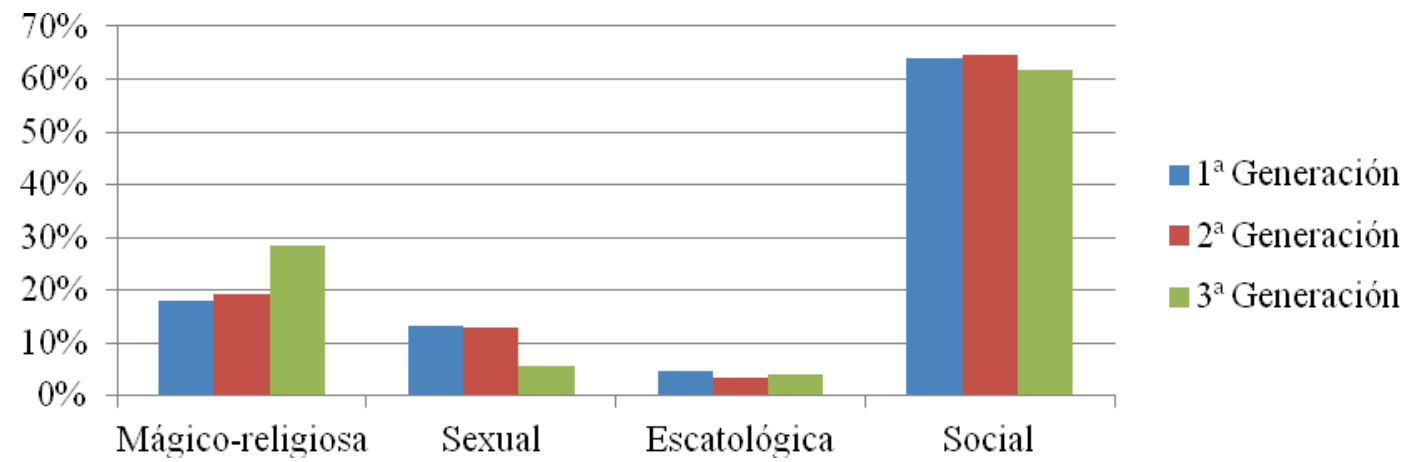


Gráfico 15. Esfera del tabú según edad

Como se observa en el gráfico 16, no existen grandes diferencias entre los datos del tabú en los corpus PRESEEA-Madrid y el PRESEEA-Granada, solamente destaca que los jóvenes madrileños se distancian bastante del resto en la esfera sexual.

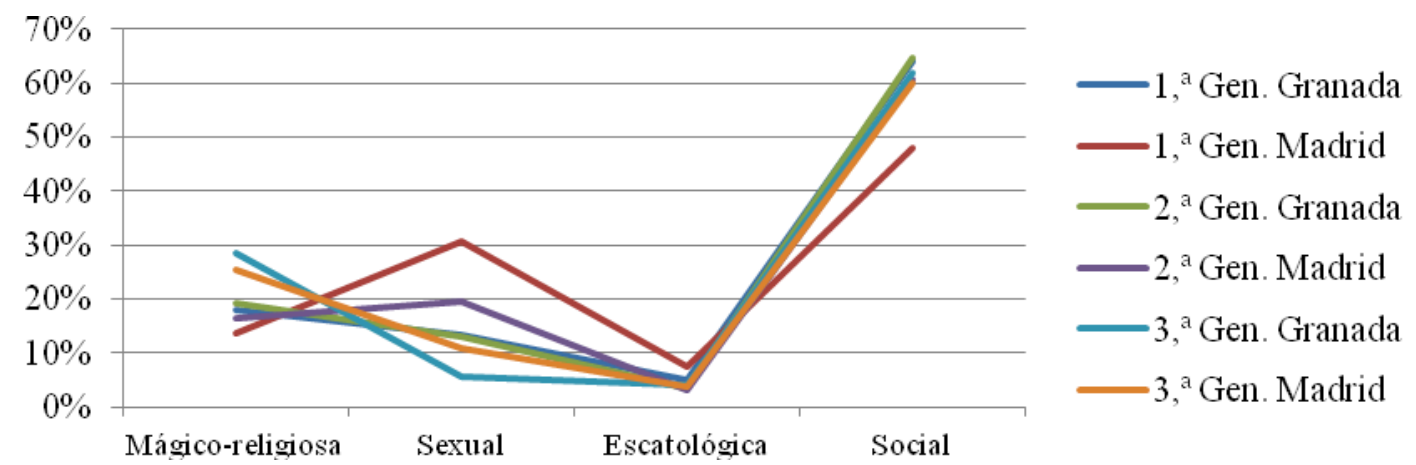

Gráfico 16. Esfera del tabú según edad en Granada y en Madrid

Si se cruza cada variable dependiente con la variable pragmática tipo de expresión y la edad se obtienen unos datos cuya expresión esquemática se refleja en el gráfico 17.

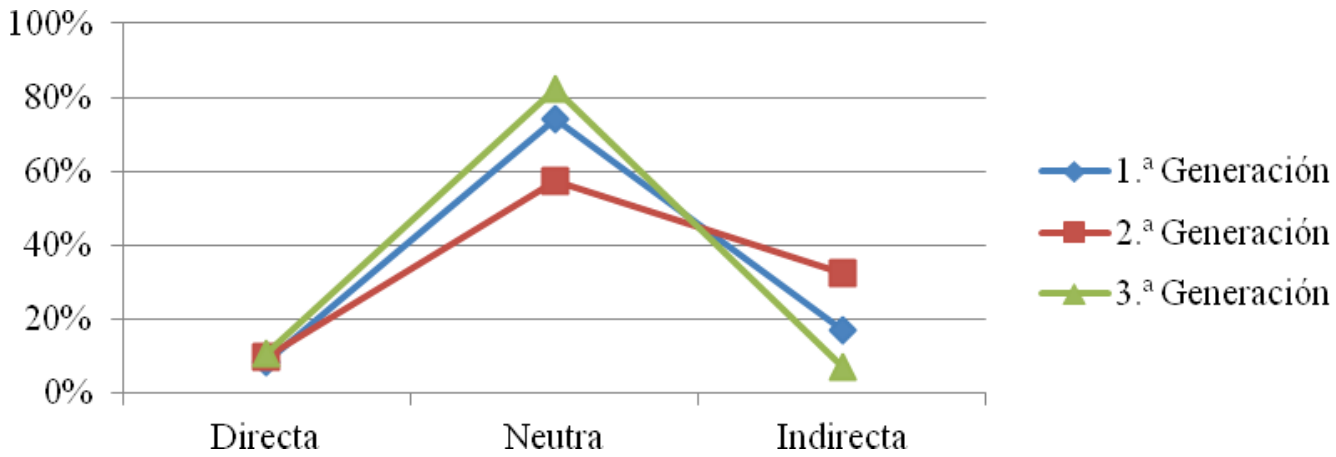

Gráfico 17. Tipo de expresión en la esfera mágico-religiosa: edad

En cuanto a la esfera mágico-religiosa, existe una relativa igualdad de comportamiento de las tres generaciones. Las tres arrojan unos valores muy cercanos en la estrategia directa (I: 10\%, II: 8.3\%, III: 10.7\%), elevan sus índices en la neutra (I: $74.3 \%$, II: $57.5 \%$, III: $82.1 \%$ ) y vuelven a descender en la indirecta (I: 17\%, II: 32.5\%, III: 7.1\%). En general, las tres generaciones se refieren a esta esfera utilizando la estrategia neutra.

En el análisis de los hablantes de segunda generación se observa que, en general, las referencias indirectas a la esfera mágico-religiosa se centran en aligerar la carga negativa de enfermedades o de la muerte (por ejemplo, «ya no está con nosotros» o «malucha»). Por otro lado, los hablantes de segunda generación se muestran reticentes a referirse a esta esfera de manera directa. Por último, las expresiones neutras tampoco parecen representar la iniciativa propia de esta generación en tanto en cuanto las ocurrencias son expresiones hechas muy comunes y de larga tradición (por ejemplo, «Dios mío», «Por Dios» o «Gracias a Dios»).

En cuanto a la esfera sexual, los casos registrados para la tercera generación han sido tan solo 11, de los cuales, el $10.7 \%$ se refieren a la estrategia directa, el $82.1 \%$ a la neutra y el $7 . \%$ la estrategia indirecta. En la primera generación, en el 53.8\% de los casos se recurre a la estrategia directa, en el 11.5\%a la opción neutra y en el 34.6\% a la indirecta. En cuanto a la segunda generación, el $40.7 \%$, de los casos son utilizados de manera directa, el 14.8\% de manera neutra y el $44.4 \%$, de manera indirecta. Así, como se muestra en el gráfico 18, existe una relación de cierta similitud entre los hablantes de primera y segunda generación que difieren claramente de la tercera. 


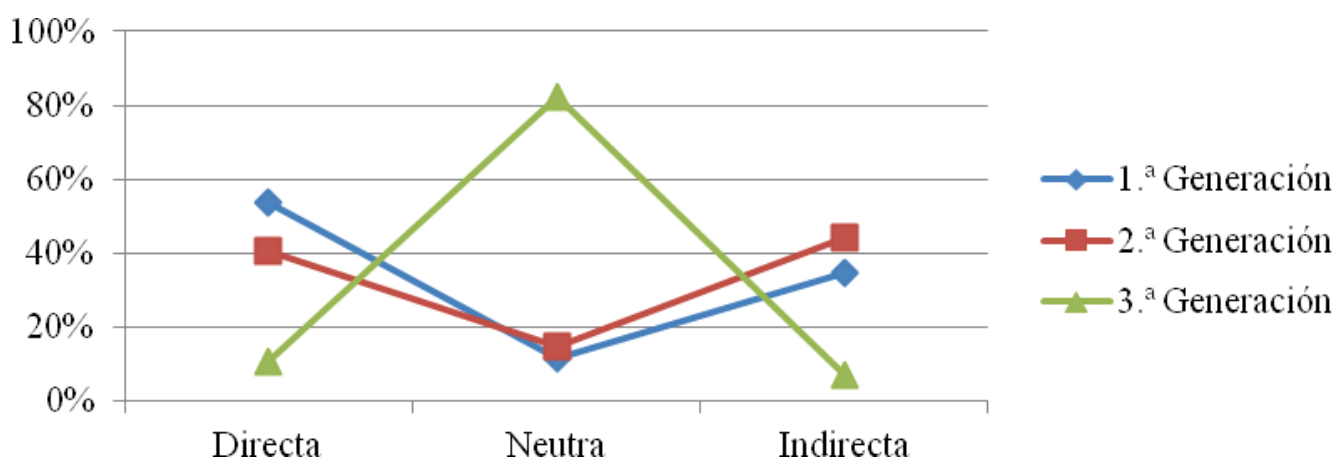

Gráfico 18. Tipo de expresión en la esfera sexual: edad

Los datos relacionados con la esfera social son muy parecidos en todas las generaciones, al igual que ocurría en el análisis por sexo. Los jóvenes emplean un 35.5\% de veces la estrategia neutra; los adultos, un 28.4\%; y los mayores, un $34.4 \%$. Asimismo, los valores de la estrategia indirecta rondan entre el $17.2 \%$ y el $20.2 \%$ de los casos y los de la estrategia directa entre el $44.4 \%$ y el $52.2 \%$.

En este caso (gráfico 19), se observa cómo los valores se distribuyen de manera inversa al grado de aceptación del tabú. Por tanto, se puede deducir que en la esfera social existen menos problemas para expresar las formas tabuizadas de manera directa.

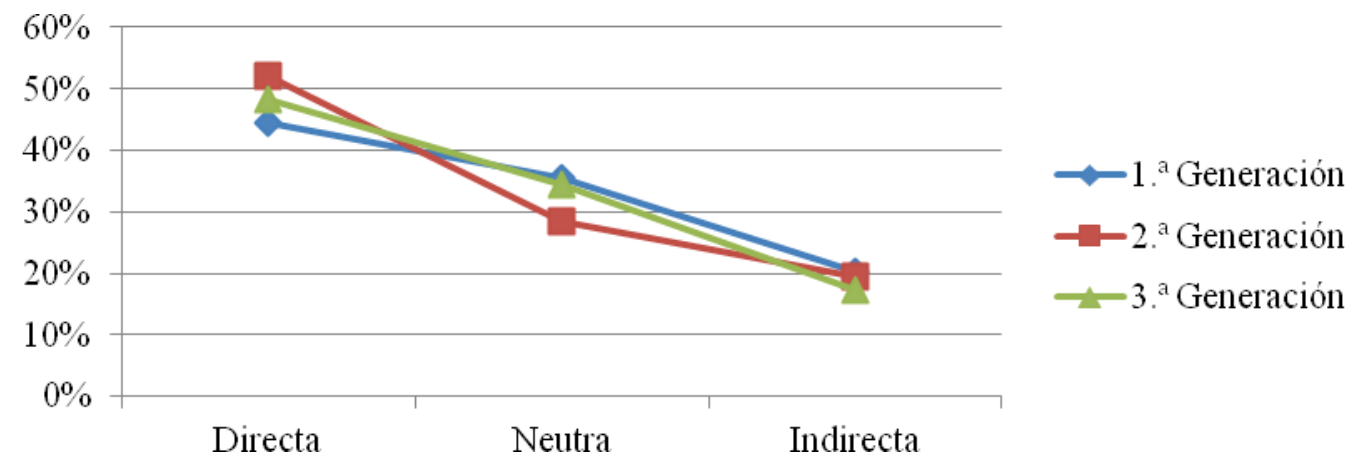

Gráfico 19. Tipo de expresión en la esfera social: edad

Por último, en cuanto a la finalidad, los granadinos de la tercera generación son los que más se refieren a las realidades tabuizadas con el fin de encubrir (9.6\%), frente a los jóvenes (6.2\%) y los adultos (7.2\%). Los que más atenúan son los jóvenes granadinos (11.3\%) frente a los adultos (9.6\%) y los mayores (7.6\%). Existe una correspondencia entre el tipo de estrategia utilizada y la finalidad discursiva. Los adultos emplean un alto porcentaje de encubrimientos o atenuaciones (un total del $16.8 \%$ ) ya que, como se ha visto al principio de este apartado, son los que más recurren a la estrategia indirecta. Por otro lado, de los casos indirectos utilizados por los jóvenes, la mayoría se emplean con el fin de atenuar.

El uso de expresiones interdictas con la finalidad de enfatizar es mayor en la segunda y la tercera generación (41.8\% y 38.6\% respectivamente). Contra lo que se esperaría tras constatar que los jóvenes recurren a la expresión directa en un 38\% de los casos, la primera generación emplea en menor proporción la finalidad enfatizar (35.1\%).

En cuanto a la variante informar, son los hablantes de la primera generación los que más la usan (47.4\%), seguidos de los adultos (41.3\%) y de los mayores (44.2\%). No obstante, las diferencias porcentuales no son demasiado grandes. Por tanto, según la edad (gráfico 20), al igual que según sexo, los hablantes granadinos arrojan datos polarizados entre encubrir y atenuar vs. enfatizar e informar.

Nuevamente (gráficos 11 y 20) sexo y generación ofrecen unos patrones de funcionamiento similares. Con anterioridad se ha podido ver este mismo patrón en lo referente a la esfera social (gráficos 10 y 19). 


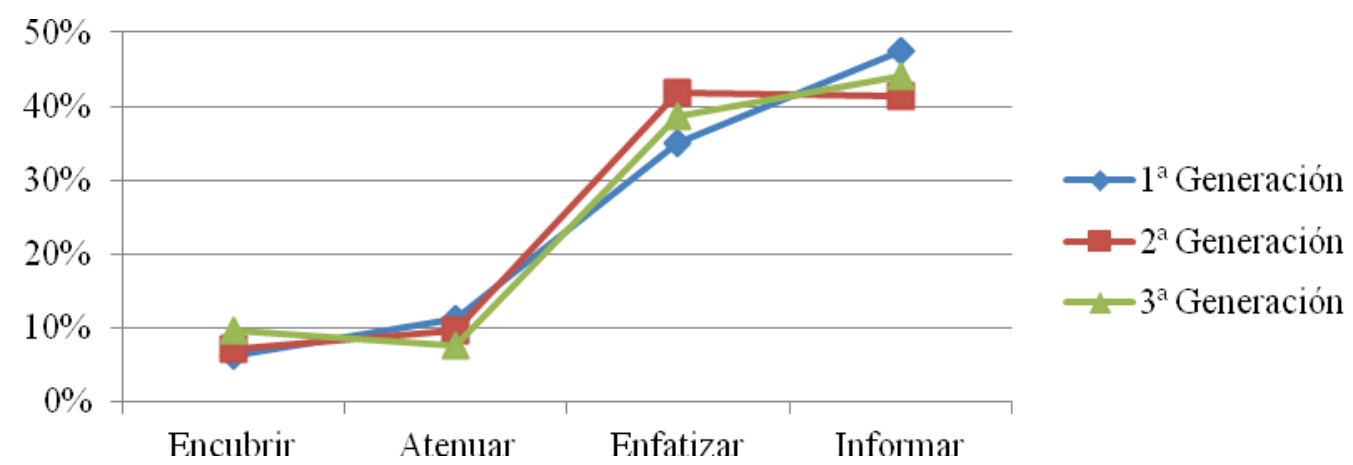

Gráfico 20. Finalidad del tabú según edad

Al igual que ocurría según la variable sexo, en el análisis de Madrid, Cestero recoge datos que difieren de los hallados en el corpus de Granada (gráfico 21). En Madrid la tercera generación apenas expresa el tabú con el fin de enfatizar, mientras que en Granada los mayores incluso enfatizan más que los jóvenes. En resumen, se puede afirmar que mientras Madrid sigue un esquema más o menos uniforme entre encubrir, atenuar y enfatizar, Granada sigue en esta ocasión también un patrón polarizado.

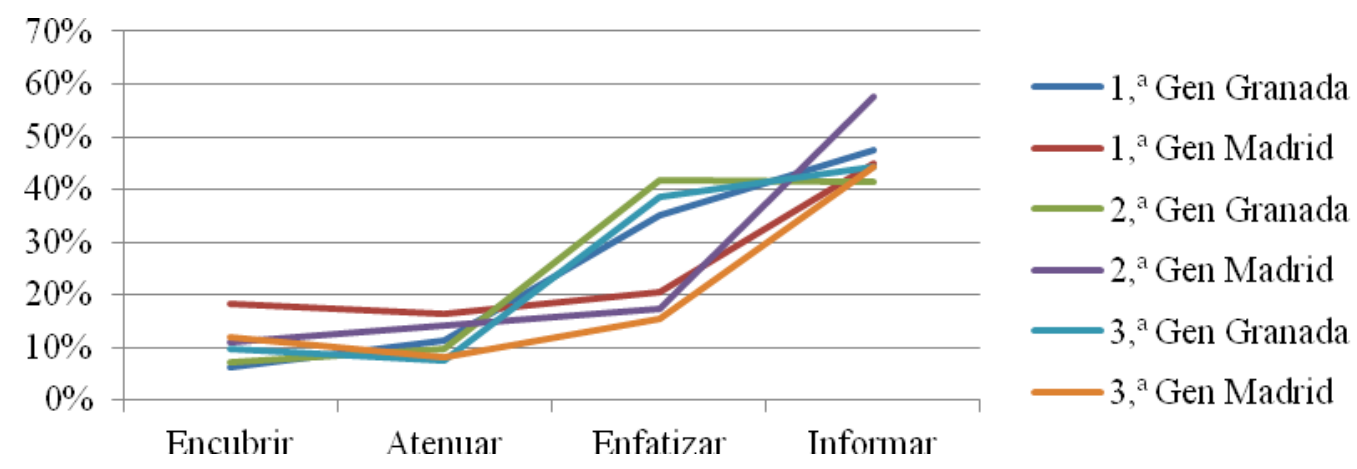

Gráfico 21. Finalidad de tabú según edad en Granada y Madrid

\subsection{Variable nivel de instrucción}

Los entrevistados con nivel de instrucción bajo son los que más usan la estrategia directa (52.8\% frente al $33.7 \%$ y el $20.4 \%$ del nivel medio y alto, respectivamente). Los de nivel de instrucción bajo utilizan menos expresiones indirectas (16\%) que los de nivel medio (22.3\%) y alto (32.4\%). Finalmente, dominan las expresiones neutras en los niveles de instrucción medio y alto (44\% y $47.2 \%$ respectivamente) y se emplea menos en el nivel bajo de estudios (31.2\%). A menor nivel de instrucción, mayor uso de estrategia directa (gráfico 22).

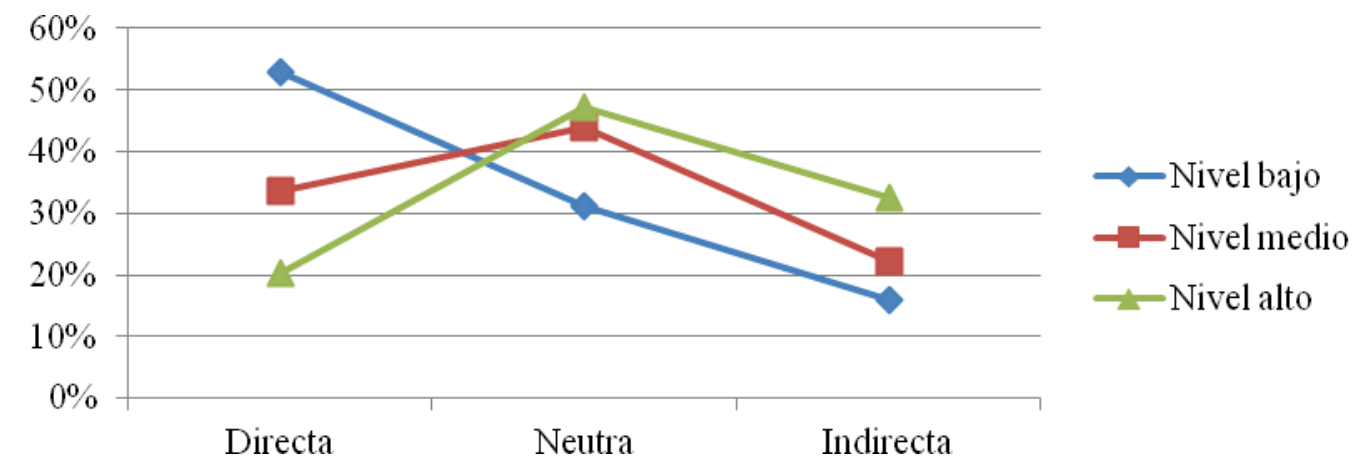

Gráfico 22. Expresión del tabú según nivel de instrucción 
Si se compara con los datos recogidos a partir del corpus PRESEEA-Madrid (gráfico 23), se observa que los hablantes madrileños de todos los niveles de instrucción emplean casi por igual las estrategias directa, neutra e indirecta. No obstante, se puede ver un patrón en el que domina fundamentalmente la expresión neutra, a diferencia del patrón granadino más equilibrado entre las tres opciones.

La distancia entre el porcentaje de expresiones recogidas en estrategia directa por los hablantes granadinos y madrileños de nivel de instrucción bajo supone alrededor de 40 puntos (gráfico 23). En cambio, los hablantes granadinos de nivel alto sí siguen, en general, el mismo patrón que los hablantes de Madrid.

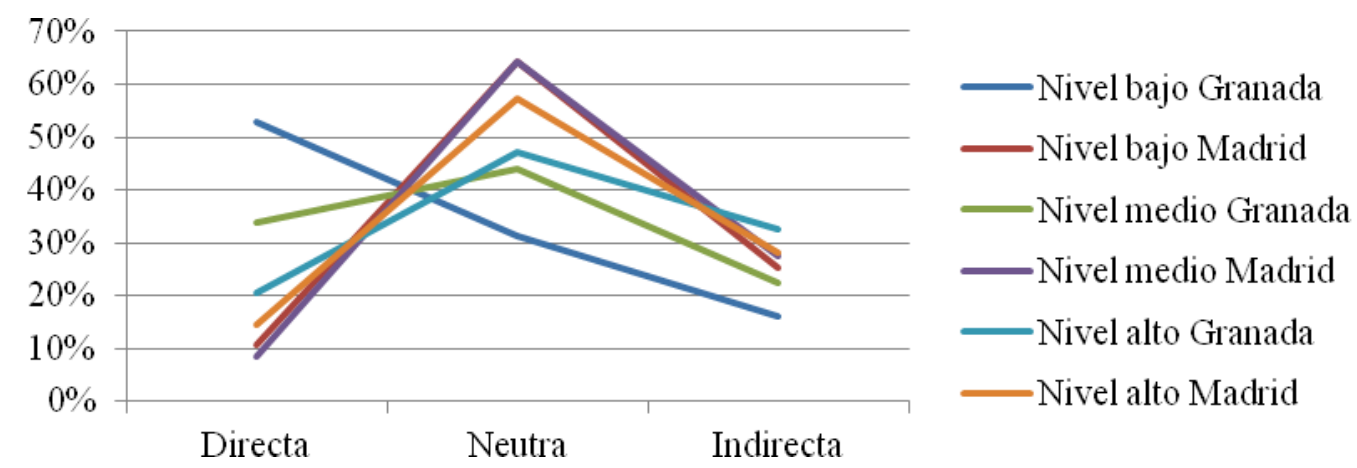

Gráfico 23. Expresión del tabú según nivel de instrucción en Granada y Madrid

En cuanto a las esferas utilizadas (gráfico 24), los hablantes del nivel de instrucción bajo y medio emplean entre un $22.9 \%$ y un $24.9 \%$ de las veces la esfera mágico-religiosa, mientras que los granadinos de nivel de instrucción alto la utilizan en menos ocasiones (16.2\% de las ocurrencias). Respecto de la esfera sexual, el nivel de instrucción medio es el que más la emplea y los niveles bajo y alto quedan por debajo del $10 \%$ de las ocasiones en las que aparece este tipo de expresiones. En cuanto a la esfera escatológica, se observa que solo un 2.1\% de la muestra corresponde a las alusiones de los hablantes de nivel de instrucción alto, el $4.9 \%$ al nivel bajo y el $4 \%$ al nivel medio. Por último, el nivel de instrucción alto es el que más utiliza la esfera social (72.5\%), seguido del nivel de instrucción bajo (63.4\%) y, finalmente, el nivel medio de estudios (56.6\%).

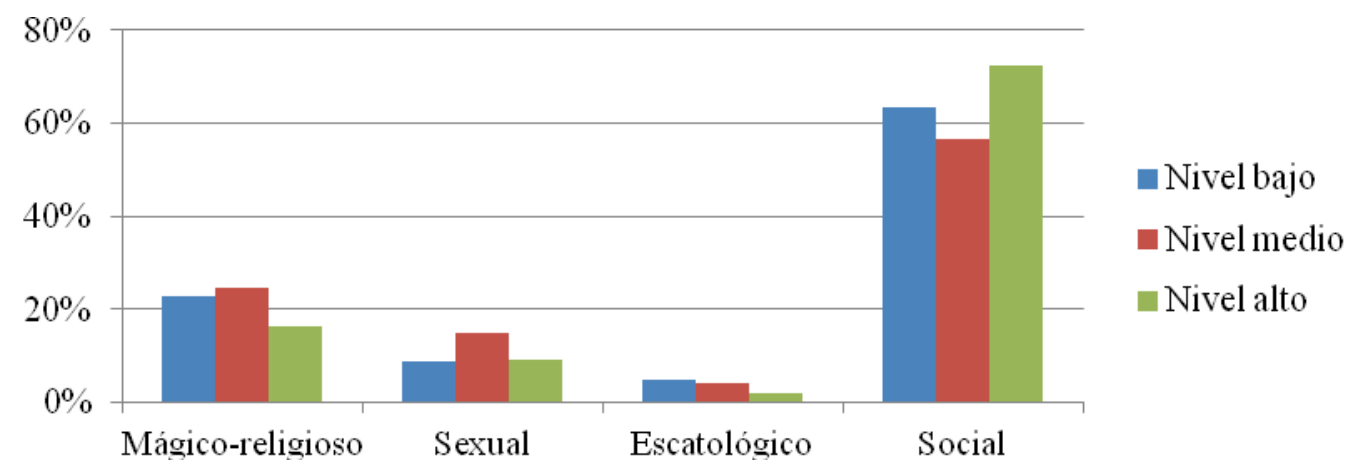

Gráfico 24. Esferas del tabú según nivel de instrucción

Cuando se comparan con el habla de Madrid (gráfico 25), se observa una distribución muy parecida excepto en la esfera sexual, donde los madrileños arrojan un mayor porcentaje de uso. 

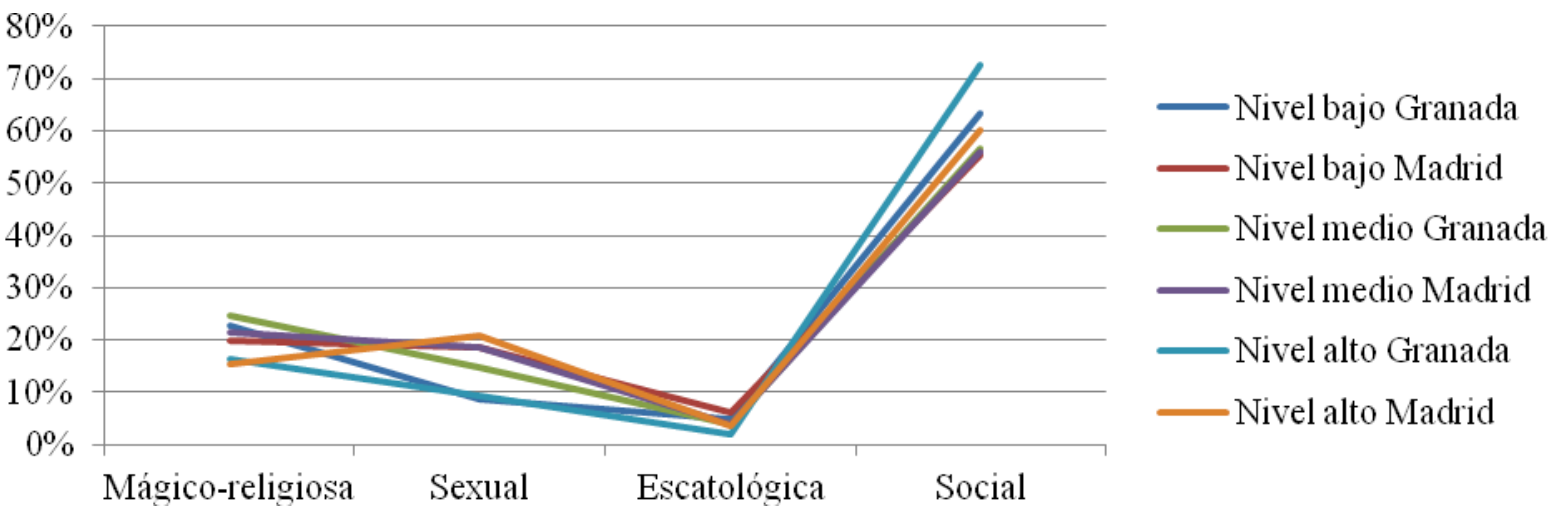

Gráfico 25. Esfera del tabú según nivel de instrucción en Granada y en Madrid

Como en los dos apartados anteriores, a continuación se expone un análisis de cada variable en función del tipo de expresión y del nivel de instrucción.

En cuanto a la esfera mágico-religiosa, los informantes de nivel de instrucción bajo son los que más recurren a la expresión directa (16.9\%), mientras que los niveles medio y alto la utilizan mucho menos (2.3\% y $4.3 \%$, respectivamente). No obstante, los de nivel de estudios bajo utilizan en la misma proporción la directa y la indirecta, y destacan en el uso de la neutra (66.2\%). En comparación con el resto, los hablantes de nivel medio y alto son los que más uso hacen de la estrategia neutra (79.1\% y $78.3 \%$ respectivamente). Asimismo, muestran resultados similares los sujetos de nivel de estudios medio y alto en cuanto a la estrategia indirecta (18.6\% y $17.4 \%$ ). Es importante destacar que, aunque en el nivel de estudios bajo la expresión directa supone un 16.9\%, muy por encima de los otros dos niveles, la mayoría de las ocurrencias son expresiones hechas, muletillas o expresiones enfáticas del tipo «iAy Dios!» o «iLa virgen!».

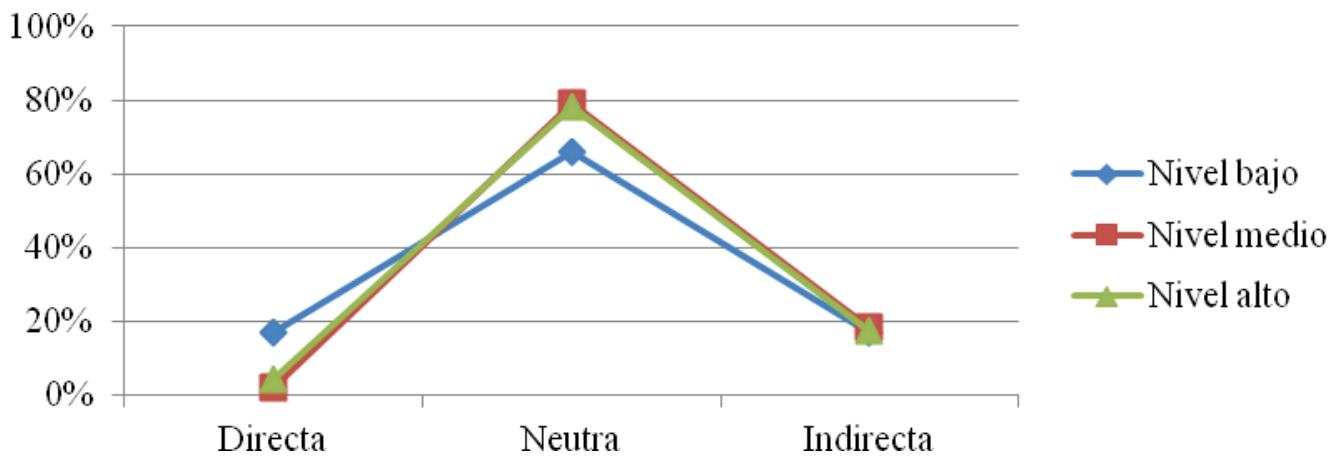

Gráfico 26. Tipo de expresión en la esfera mágico-religiosa: nivel de instrucción

En cuanto a la esfera sexual (gráfico 27), los hablantes de nivel de instrucción bajo, cuando se refieren a ella, lo hacen en estrategia directa. Totalmente a la inversa, los de nivel de instrucción alto recurre a esta esfera casi siempre en forma indirecta (84.6\%) y muy poco de forma neutra o directa (7.7\%). Por último, el nivel medio de estudios, aunque no emplea mucho la estrategia neutra (11.5\%), la estrategia indirecta y la directa están más repartidas (38.5\% y $50 \%$ respectivamente). Así, se podría decir que entre los hablantes de nivel de instrucción alto existe una gran carga de tabú en cuanto a esta esfera e intentan evitarla mediante el uso de expresiones eufemísticas. Por el contrario, los hablantes de nivel de estudios bajo son los que menos reparo presentan a referirse a la esfera sexual de manera directa, seguidos de los de nivel de estudios medio. No existen grandes diferencias entre los niveles bajo y medio, pero sí entre estos y los de nivel de estudios alto. 


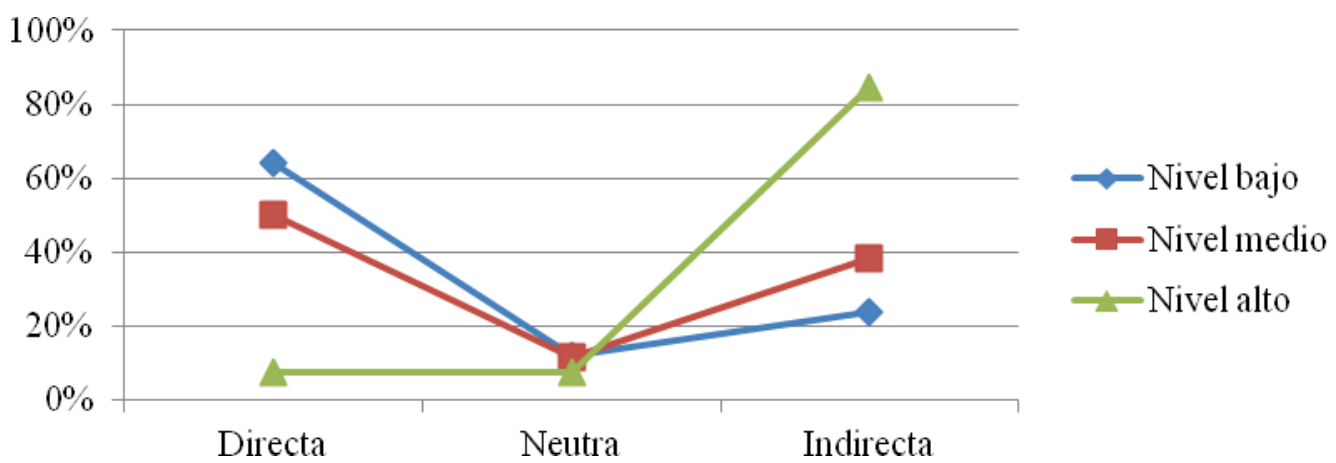

Gráfico 27. Tipo de expresión en la esfera sexual: nivel de instrucción

En la esfera escatológica (gráfico 28), los hablantes de nivel bajo y medio prefieren bien la directa o bien la indirecta (respectivamente) antes que la neutra. Sin embargo, los informantes del nivel de instrucción alto nunca se refieren a esta esfera de manera directa o indirecta y, cuando lo hacen a ella, es de manera neutra.

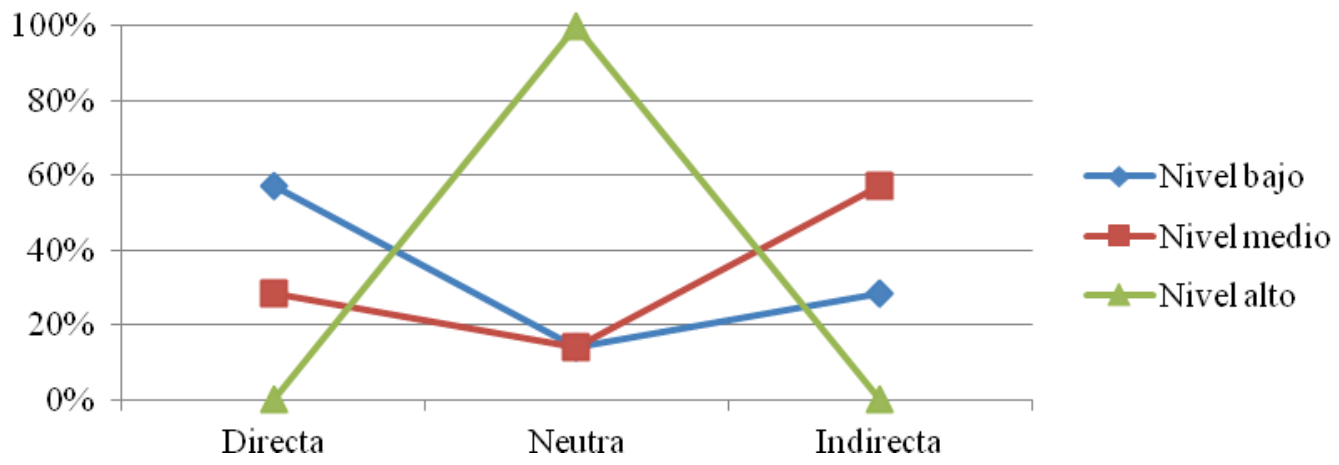

Gráfico 28. Tipo de expresión en la esfera escatológica: nivel de instrucción

En cuanto a la esfera social (gráfico 29), las diferencias no son muy notables en las variantes neutra e indirecta, pero sí en la directa. El nivel de estudios bajo se refiere a esta esfera eminentemente de forma directa, mientras que los hablantes de nivel alto y medio utilizan en menos ocasiones esta estrategia. Al contrario de lo que se ha señalado anteriormente en lo social (gráficos 10 y 19), por nivel de instrucción, los hablantes de nivel alto sí parecen tener más reparo a emplear expresiones directas.

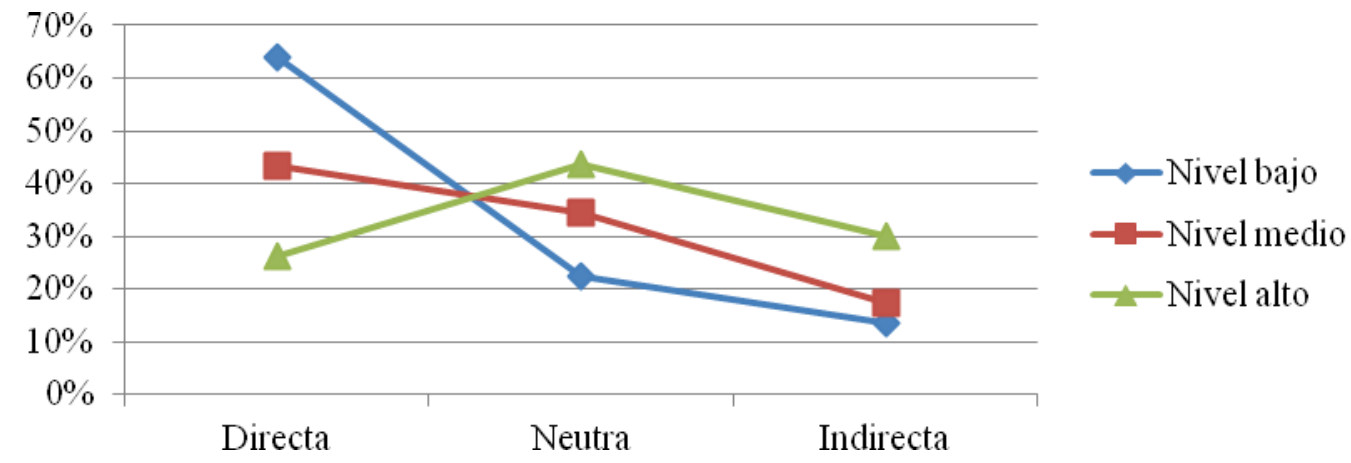

Gráfico 29. Tipo de expresión en la esfera social: nivel de instrucción

Por último, en cuanto a la finalidad con que se utilizan las expresiones que hacen referencia a realidades interdictas, el nivel de instrucción bajo y medio representan el mismo patrón de comportamiento que se viene observando en las anteriores variables (gráficos 11 y 20) donde los datos se polarizan entre encubrir y atenuar vs. enfatizar e informar. Sin embargo, el nivel alto no 
arroja datos que sigan dicho patrón. Este difiere tanto en la variante enfatizar, muy por debajo de las otras dos, como en la variante informar, por encima de las restantes.

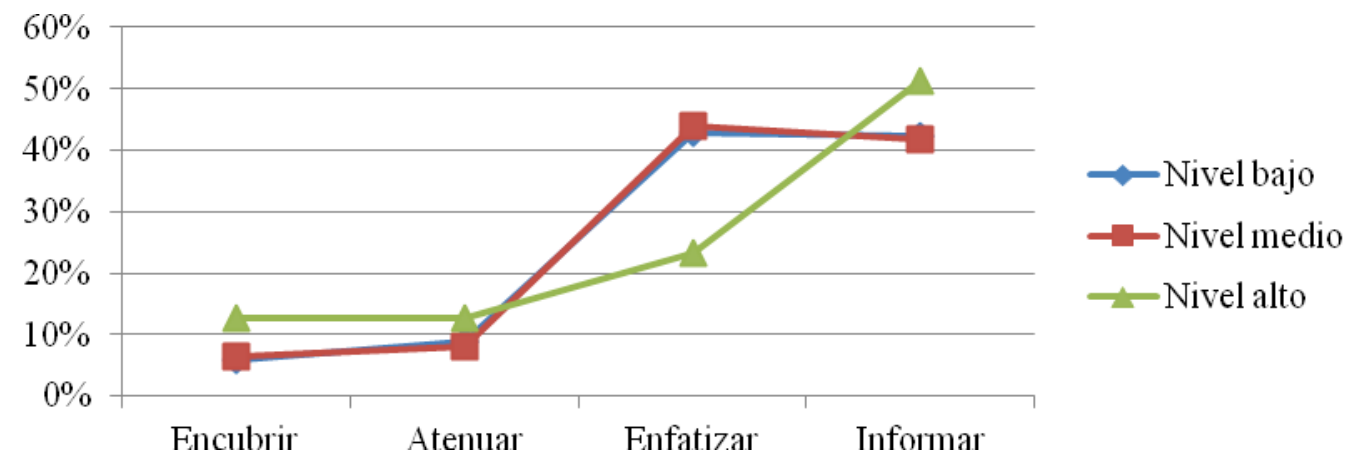

Gráfico 30. Finalidad del tabú según nivel de instrucción

En el habla de Madrid (gráfico 31), a diferencia de lo que se ha visto arriba con respecto a las variables sexo y edad (gráficos 12 y 21), el nivel de instrucción arroja una superposición casi perfecta entre los hablantes granadinos y madrileños de nivel de instrucción alto. Además, se observan otros dos patrones de comportamiento: por un lado, los hablantes granadinos de nivel de instrucción bajo y medio y, por otro lado, los hablantes madrileños de los mismos niveles. La diferencia entre ambos grupos reside en que los granadinos recurren a las variantes informar y enfatizar prácticamente de la misma forma mientras que los madrileños enfatizan muy poco e informan muy por encima del resto.

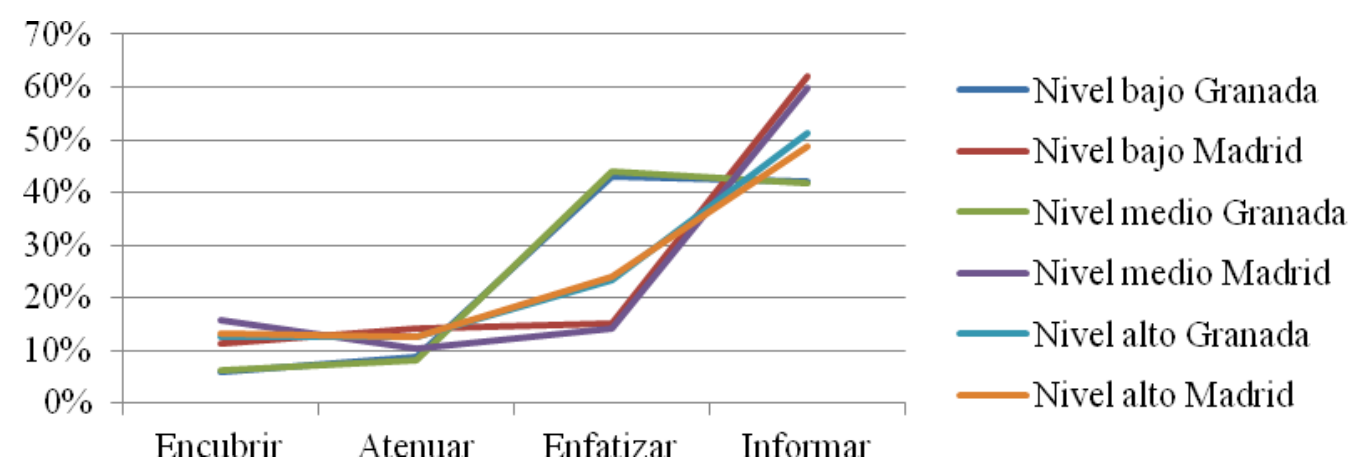

Gráfico 31. Finalidad de tabú según nivel de instrucción en Granada y Madrid

\section{CONCLUSIONES}

El análisis cuantitativo de los resultados obtenidos para el corpus PRESEEA-Granada ha conducido a las siguientes conclusiones, que intentan responder a las hipótesis de investigación señaladas anteriormente.

En primer lugar, se ha podido comprobar que los datos obtenidos arrojan valores diferentes según el sexo, la edad o el nivel de instrucción del hablante.

Como se planteaba en la hipótesis, las mujeres y los hombres no se comportan igual cuando se refieren a conceptos o realidades interdictas. Aunque se recoge el mismo número de entradas para hombres y para mujeres, se demuestra la hipótesis inicial de que las mujeres utilizan menos las esferas sexual y escatológica y los hombres, más. En general, las mujeres recurren más a la estrategia neutra que los hombres. Sin embargo, se ha observado que, cuando expresan unidades pertenecientes a las esferas sexual y escatológica, las mujeres prefieren la estrategia directa, mientras que los hombres prefieren la neutra y la indirecta. Finalmente, aunque ambos sexos enfatizan y encubren igual, las mujeres informan más y atenúan menos que los hombres.

Por otro lado, se ha observado que los hablantes de tercera generación utilizan la esfera mágicoreligiosa más que las otras dos generaciones y que, cuando la emplean, lo hacen principalmente en estrategia neutra. En general, la tercera generación es la que más emplea las expresiones neutras y 
la segunda generación, las directas. No obstante, dentro de la esfera mágico-religiosa, todos los grupos generacionales rechazan la estrategia directa, lo que hace pensar que, en general, esta esfera suscitaría cierto respeto independientemente de la edad. Además, con estos datos se puede corroborar la hipótesis de que la referencia a la esfera mágico-religiosa se formula fundamentalmente en estrategia neutra, sin marcas. La primera generación es la que menos enfatiza y la que más atenúa en comparación con las otras dos generaciones.

Según el nivel de instrucción de los hablantes, el nivel bajo es el que más referencia hace a conceptos o realidades tabuizadas y es el que más utiliza la esfera escatológica, de forma directa principalmente. El nivel medio se refiere más a la esfera mágico-religiosa (de forma neutra) y sexual (de forma directa). El nivel alto se centra en la esfera social y se refiere a ella de manera neutra e indirecta. Tanto el nivel alto como el medio prefieren la estrategia neutra y el nivel bajo, la directa. Por último, los hablantes de niveles medio y bajo enfatizan e informan más, mientras que los de nivel alto casi nunca enfatizan y, además, encubren y atenúan más que los otros dos grupos de hablantes.

En segundo lugar, también se ha confirmado la hipótesis de que la caracterización de las expresiones o conceptos interdictos depende de la finalidad y la función dentro del contexto discursivo ya que una misma expresión se ha podido clasificar como expresión directa (disfemística) o como expresión neutra (ortofemística) dependiendo del contexto. Se ha observado que la función expresiva sin valor se concentra exclusivamente en la finalidad enfatizar y, en consecuencia, se puede afirmar que los hablantes eligen la función expresiva para enfatizar su mensaje.

En tercer lugar, según las comparaciones llevadas a cabo a lo largo del análisis, se puede afirmar que, en general, los hablantes de Granada y los de Madrid coinciden en el uso de las distintas esferas. Sin embargo, los hablantes muestran diferencias significativas por edad y nivel de instrucción y, sobre todo, en el análisis de finalidades,polarizados en el caso de Granada y ascendentes en el caso de Madrid.

\section{REFERENCIAS BIBLIOGRÁFICAS}

Allan, Keith y Kate Burridge (2006): Forbidden words, Nueva York, Cambridge University Press.

Calvo Shadid, Annette (2008): Análisis sociolingüístico sobre el tabú sexual en el español de Costa Rica, Tesis doctoral, Bergen, Universidad de Bergen.

Calvo Shadid, Annette (2011): «Sobre el tabú, el tabú lingüístico y su estado de la cuestión", Kañina, Revista Artes y Letras, Universidad de Costa Rica XXXV (2), 121-145.

Casas Gómez, Miguel (2005): «Precisiones conceptuales en el ámbito de la interdicción lingüística» en Santos Ríos, Luis, ed., Palabras, norma, discurso: en memoria de Fernando Lázaro Carreter, Salamanca, Ediciones Universidad de Salamanca, 271-290.

Casas Gómez, Miguel (2012a): «De una visión léxica y pragmático-discursiva a una dimensión cognitiva en la caracterización extralingüística y lingüística del eufemismo» en Fuentes Rodríguez, Catalina y Esperanza R. Alcaide Lara, eds., Manifestaciones textuales de la descortesía y agresividad verbal en diversos ámbitos comunicativos, Sevilla, Universidad Internacional de Andalucía, 11-29.

Casas Gómez, Miguel (2012b): «El realce expresivo como función eufemística: a propósito de la corrección política de ciertos usos lingüísticos" en Reutner, Úrsula y Elmar Schafroth, eds., Political Correctness, Frankfurt am Main, Peter Lang, 61-77.
Cestero Mancera, Ana María (2015a): «Estudio sociolingüístico del tabú en el habla de Madrid: propuesta metodológica y primeros resultados» en Cestero Mancera, A. María, Isabel Molina Martos y Florentino Paredes García, eds., Patrones sociolingüísticos de Madrid, Frankfurt am Main: Peter Lang, 287348.

Cestero Mancera, Ana María (2015b): «La expresión del tabú: estudio sociolingüístico», Boletín de Filología, Chile, Universidad de Chile.

Crespo Fernández, Eliecer (2007): El eufemismo y el disfemismo. Procesos de manipulación del tabú en el lenguaje literario inglés, Alicante, Publicaciones Universidad de Alicante.

Drange, Eli-Marie Danbolt (1997): La mujer y el tabú. Un análisis sociolingüístico del tabú en el lenguaje femenino de Viña del Mar, Tesis de máster inédita, Bergen, Universidad de Bergen.

García Platero, Juan Manuel (2010): «Usos afijales descorteses en registros formales", Discurso y Sociedad 4(4), 813.

Grimes, Larry (1978): El tabú lingüístico en México: el lenguaje erótico de los mexicanos, Nueva York, Bilingual Review Press.

Hernández Campoy, Juan Manuel y Manuel Almeida (2005): Metodología de la investigación sociolingüística, Málaga, Comares.

Kany, Charles E. (1960): American-Spanish Euphemism, Berkeley and Los Angeles, University of California Press. 
Lavob,William (1983): Modelos sociolingüísticos, Madrid, Cátedra.

Leach, Edmund (1967): «Anthropological aspects of language: animal categories and verbal abuse» en $H$. Lenneberg, Eric, ed., New directions in the study of language, Cambridge, The MIT Press, 23-63.

López Morales, Humberto (1990): Sociolingüística del tabú. El caso de Puerto Rico, Madrid, MS.

López Morales, Humberto (1994): Métodos de investigación lingüística, Salamanca, Ediciones del Colegio de España.

López Morales, Humberto (2001): «Estratificación social del tabú lingüístico: el caso de Puerto Rico» en De Jonge, Bob, ed., Estudios de lingüística del español 13. Holanda, Universidad de Groningen.

López Morales, Humberto (2005): «Sociolingüística del tabú» en Interlingüística 16(1), 7-20.

Martínez Valdueza, Pilar (1995): El tabú lingüístico: estudio sociolingüístico de Las Palmas de Gran Canaria, Tesis doctoral inédita, Las Palmas de Gran Canaria, Universidad de las Palmas.

Martínez Valdueza, Pilar (1998): «Status quaestionis: el tabú lingüístico", Lingüística 10, 115-139.

Milroy, Lesley y Matthew Gordon (2003): Sociolinguistics. Method and Interpretation, Oxford, Blackwell.

Montero Cartelle, Emilio (1981): El eufemismo en Galicia (Su comparación con otras áreas romances) Verba. Anuario Galego de Filoloxia Anejo 17, Santiago de Compostela, Universidade de Santiago de Compostela.

Moreno Fernández, Francisco (1990): Metodología Sociolingüística, Madrid, Gredos.

Moya Corral, Juan Antonio coord. (2007-9): El español hablado en Granada. Corpus oral para su estudio sociolingüístico. Nivel de estudios alto, medio y bajo, 3 vols., Granada, Universidad de Granada.

Pizarro Pedraza, Andrea (2013): Tabú y eufemismo en la ciudad de Madrid. Estudio sociolingüístico-cognitivo de los conceptos sexuales, Tesis doctoral inédita, Madrid, Universidad Complutense de Madrid. 